\title{
The Benyvirus RNA Silencing Suppressor Is Essential for Long-Distance Movement, Requires Both Zinc-Finger and NoLS Basic Residues but Not a Nucleolar Localization for Its Silencing-Suppression Activity
}

\author{
Sotaro Chiba, ${ }^{1,2}$ Kamal Hleibieh, ${ }^{1}$ Alice Delbianco, ${ }^{1,3}$ Elodie Klein, ${ }^{1}$ Claudio Ratti, ${ }^{3}$ \\ Véronique Ziegler-Graff, ${ }^{1}$ Salah Bouzoubaa, ${ }^{1}$ and David Gilmer ${ }^{1}$ \\ ${ }^{1}$ Institut de Biologie Moléculaire des Plantes, Laboratoire Propre du CNRS (UPR 2357) Conventionné avec l'Université de \\ Strasbourg, 12 rue du Général Zimmer, 67084 Strasbourg, France; ${ }^{2}$ Institute of Plant Science and Resources, Okayama \\ University, 2-20-1 Kurashiki, Japan; ${ }^{3}$ Università di Bologna, Dipartimento di Scienze e Tecnologie Agroambientali Area \\ Patologia Vegetale, Viale G. Fanin, 40, II piano 40127, Bologna, Italy
}

Submitted 1 June 2012. Accepted 20 September 2012.

\begin{abstract}
The RNA silencing-suppression properties of Beet necrotic yellow vein virus (BNYVV) and Beet soil-borne mosaic virus (BSBMV) cysteine-rich p14 proteins have been investigated. Suppression of RNA silencing activities were made evident using viral infection of silenced Nicotiana benthamiana $16 \mathrm{C}, N$. benthamiana agroinfiltrated with green fluorescent protein (GFP), and GF-FG hairpin triggers supplemented with viral suppressor of RNA silencing (VSR) constructs or using complementation of a silencing-suppressor-defective BNYVV virus in Chenopodium quinoa. Northern blot analyses of small-interfering RNAs (siRNAs) in agroinfiltration tests revealed reduced amounts of siRNA, especially secondary siRNA, suggesting that benyvirus VSR act downstream of the siRNA production. Using confocal laser-scanning microscopy imaging of infected protoplasts expressing functional p14 protein fused to an enhanced GFP reporter, we showed that benyvirus p14 accumulated in the nucleolus and the cytoplasm independently of other viral factors. Site-directed mutagenesis showed the importance of the nucleolar localization signal embedded in a $\mathrm{C} 4$ zinc-finger domain in the VSR function and intrinsic stability of the p14 protein. Conversely, RNA silencing suppression appeared independent of the nucleolar localization of the protein, and a correlation between BNYVV VSR expression and long-distance movement was established.
\end{abstract}

During host infection, viruses face plant antiviral defense, particularly the innate response targeting double-stranded RNA arising from viral RNA genome replication. Such an antiviral mechanism, known as RNA interference (RNAi) or posttranscriptional gene silencing (PTGS), is widely distributed among eukaryotes (Ding 2010; Ding and Voinnet 2007; Voinnet 2001, 2005, 2008). This extensively explored mechanism pro-

S. Chiba, K. Hleibieh, and A. Delbianco contributed equally to this work.

Corresponding author: David Gilmer; Telephone: +33367155362; Fax: +33388614442; E-mail: david.gilmer@ibmp-cnrs.unistra.fr

*The $\boldsymbol{e}$-Xtra logo stands for "electronic extra" and indicates one supplementary figure is published online.

(C) 2013 The American Phytopathological Society vides detailed characterization of the pathways involving the cleavage of double-stranded RNA by dicer-like proteins (Deleris et al. 2006; Moissiard and Voinnet 2006), the loading of small-interfering RNAs (siRNAs) into ARGONAUTE complexes and their slicer activity (Azevedo et al. 2010; Duan et al. 2012; Ruiz-Ferrer and Voinnet 2007), as well as transitivity provided by endogenous RNA-dependent RNA polymerases (Moissiard et al. 2007). Many if not all steps of this defense mechanism are targets of viral elements, known as viral suppressors of RNA silencing (VSR) (Li and Ding, 2006), that tend to inhibit or inactivate one or more of the silencing machinery actors (Burgyan and Havelda 2011). Thus, VSR provide important insight in the understanding of RNA silencing and are used as powerful molecular probes to elucidate some biochemical silencing steps (Voinnet 2005). Due to their wide structural diversity and primary functions, VSR identification per se is difficult even when they were already described as pathogenicity factors (Brigneti et al. 1998). VSR described thus far belong to structural proteins (e.g., Carmovirus p38) or to nonstructural proteins involved in replication (e.g., Tobamovirus spp.), movement (e.g., Potexvirus spp.), vector transmission (e.g., Potyvirus spp. HC-Pro) or to yet unidentified primary function (e.g., Polerovirus spp. P0). Subcellular localizations of VSR have been shown to vary greatly because some accumulate in either the cytoplasm, peroxisomes, nucleus, or nucleolus. Some experiments have provided a link between VSR activities and the subcellular localization of the proteins but these remain poorly documented. The subcellular localization of a protein could affect functions, by regulating either its concentration or degradation; therefore, it appears essential to study the fate of a VSR during the infection cycle and correlate its activity with its subcellular targeting.

Benyviruses belong to class IV of the Baltimore classification (Baltimore 1971) and consist of positive-stranded multipartite RNA viruses transmitted by the protozoa Polymyxa betae (Gilmer and Ratti 2012). Within the genus Benyvirus, Beet necrotic yellow vein virus (BNYVV) and Beet soil-borne mosaic virus (BSBMV) share common properties but are distinct species, while the closely related bipartite Burdock mottle virus (BdMoV) and Rice stripe necrosis virus (RSNV) (Lozano and Morales 2009) are tentative members of the Benyvirus genus. Out of the five BNYVV RNAs, RNA1 and 2 are carried by all BNYVV strains isolated from fields (Chiba et al. 2011;

168 / Molecular Plant-Microbe Interactions 
Schirmer et al. 2005) and are sufficient to establish an infection on some mechanical hosts, indicating that housekeeping functions are all present within these two components (Peltier et al. 2008). In such conditions, smaller RNAs (RNA3, RNA4, and RNA5) are dispensable and have been engineered as expression vectors for protein of interest (Schmidlin et al. 2005), although they have beneficial roles in natural infection (Peltier et al. 2008).

Genetic, biochemical, and viral complementation screens are commonly used to identify and characterize VSR ( $\mathrm{Li}$ and Ding 2006). Such descriptions of silencing suppressors include complementation of VSR defective viruses, infection of silenced plants, as well as patch test experiments (Angell and Baulcombe 1997; Brigneti et al. 2004; Ratcliff et al. 2001; Voinnet et al. 2003). Such tools were used to screen for silencing suppressor activity of BNYVV and confirmed the VSR function of BNYVV p14 (Andika et al. 2012; Dunoyer et al. 2002; Guilley et al. 2009; Kozlowska-Makulska et al. 2010; Zhang et al. 2005). Moreover, they identified BdMoV p13 as a VSR (Guilley et al. 2009).

In this article, we highlight the properties of benyvirus p14 proteins. We show that BNYVV and BSBMV p14 proteins act downstream of the initial steps of the silencing response. P14 VSR are zinc-finger (Znf) cysteine-rich proteins (CRP) that are addressed to the nucleolus of infected cells by the presence of basic amino acids embedded in the Znf (Niesbach-Klosgen et al. 1990). Sequence motives required for nucleolar targeting, dimer formation, and cysteine residues essential to the $\mathrm{Znf}$ structure folding of BNYVV p14 protein have been identified. Our work also shows that the ability of BNYVV to suppress the RNAi defense mechanism is not related to the p14 nucleolar localization. Finally, we demonstrate that the p14-silencing-suppressor function is essential for an efficient systemic spread of the virus in two experimental host plants.

\section{RESULTS}

\section{Benyvirus p14 CRP are VSR.}

Viral infection of green fluorescent protein (GFP)-silenced Nicotiana benthamiana $16 \mathrm{C}$ plants, that initially express constitutively the GFP gene under the $35 \mathrm{~S}$ promoter, revealed restoration of GFP expression in stem and mesophyll tissues of Peanut clump virus (PCV)-infected plants (Dunoyer et al. 2002) whereas BNYVV-infected plants displayed only limited reappearance of the fluorescence (Fig. 1A, middle panel): GFP mRNA was detected mainly in the stem and leaf veins (Fig. 1A, right panel, lanes s and v; GFP) although BNYVV RNA1 and 2 were found in all $N$. benthamiana tissues (Fig. 1A, right panel, lanes s, v, and m; RNA1 and RNA2). Conversely, no fluorescence was present on mock-inoculated silenced plants where GFP mRNA was at the detection limit when compared with nonsilenced $16 \mathrm{C}$ plants. Earlier studies showed that the CRP expressed from an RNA2-derived subgenomic RNA displays VSR activity (Dunoyer et al. 2002; Gilmer et al. 1992; Koonin et al. 1991).

P14-deficient BNYVV can be complemented by other VSR proteins and, in particular, by the p15 CRP of PCV (Guilley et al. 2009) and by BSBMV p14 expressed from a replicon vector (data not shown), suggesting similar functions for both benyvirus VSR proteins. Sequence comparisons of benyvirus CRP using the MAFFT software (Katoh and Toh 2008) allowed us to define conserved cysteine residues (Fig. 1B, blue boxes). Using the NoD algorithm (Scott et al. 2011), a putative nucleolus localization signal (NoLS) was predicted between residues 66 and 90 (Fig. 1B, underlined in red). No such NoLS motif was identified on BSBMV p14 and the two Benyvirus tentative members BdMoV and RSNV CRP. We compared the silenc- ing-suppression activities of BNYVV and BSBMV p14 proteins (p14-BN and p14-BS, respectively) to that of the known polerovirus P0 VSR (Fig. 1C) by agroinfiltration tests using $N$. benthamiana 16C plants. Co-infiltration of bacteria carrying the GFP-silencing trigger construct and an empty binary vector resulted in the extinction of GFP expression. Moreover, the appearance of specific GFP siRNAs in the patched area 4 days postinfiltration indicated the induction of the GFP mRNA silencing (Fig. 1C, Ø). When the Turnip yellows virus (TuYV) P0 VSR was co-expressed with the GFP construct, the fluorescence intensity of the patches markedly increased (not shown); this was correlated to a strong increase of the GFP mRNA and a decrease of GFP siRNAs accumulation (Fig. 1C, P0). When benyvirus VSR were expressed, the fluorescence of the patches became brighter (not shown) and a reduction of GFP siRNAs was observed (Fig. 1C, p14-BN and p14-BS). The amount of GFP mRNA was efficiently increased with p14-BS and only slightly increased with p14-BN. However, when the influenza hemagglutinin A epitope (HA) tag was added to the $\mathrm{N}$-terminus of the p14-BS protein, the VSR activity was reduced (Fig. 1C, compare p14-BS and HA:p14-BS). The silencing-suppression effect of both benyvirus CRP diminished after 4 days, while that of P0 VSR was maintained even after 7 days (data not shown).

\section{Benyvirus p14 CRP act downstream of primary siRNA production.}

We then conducted similar experiments on $N$. benthamiana wild-type (wt) plants infiltrated with pBin-GFP and VSR together with a GF-FG hairpin trigger (Himber et al. 2003) corresponding to the $5^{\prime}$ part of the GFP mRNA. We analyzed the production of primary and secondary "GF" siRNAs as well as secondary "P" siRNAs produced by the transitivity pathway (Himber et al. 2003; Moissiard et al. 2007). In the control experiment, Turnip crinkle virus (TCV) P38 VSR expression dramatically reduced the accumulation of both primary and secondary siRNAs and increased that of GFP (Fig. 1D, P38TCV), as previously reported. However, we were unable to show any increase in the accumulation of GFP mRNA (Azevedo et al. 2010; Deleris et al. 2006). The use of TuYV P0 VSR induced the accumulation of both the GFP mRNA and GFP protein. As expected, P0 suppressor activity did not affect the primary siRNA production but reduced secondary siRNA accumulation (Bortolamiol et al. 2007). When benyvirus CRP were expressed in the presence of the hairpin trigger, GFP messenger and GFP protein levels increased compared with those of the negative control experiment but were lower than those produced by P0 (Fig. 1D). GF siRNAs were reduced in the presence of BNYVV CRP but were comparable with those produced in the absence of VSR when BSBMV CRP was used. A reduction of secondary $\mathrm{P}$ siRNAs was observed using both benyvirus CRP, suggesting that p14 CRP did not fully inhibit the transitivity mechanism per se. Again, the HA-tagged BSBMV p14 exhibited less efficient VSR activity compared with the wt p14BS because more GF siRNAs were detected for similar loading (Fig. 1D). A comparable effect of an HA tag was described for tombusvirus p19 that lost 50\% of its suppression activity (Dunoyer et al. 2004).

\section{BNYVV p14 CRP is a cytoplasmic and nucleolar protein.}

In order to investigate the subcellular localization of the BNYVV p14 CRP, its sequence was fused to that of enhanced (E)GFP (Fig. 2A) in the BNYVV rep0 replicon vector (Guilley et al. 2009; Jupin et al. 1990; Schmidlin et al. 2005) to produce in vitro transcripts. These transcripts were co-inoculated to tobacco BY-2 protoplasts with BNYVV RNA1 and either an RNA2 deficient in p14 expression (RNA2 $\Delta$ p14) or a wt 

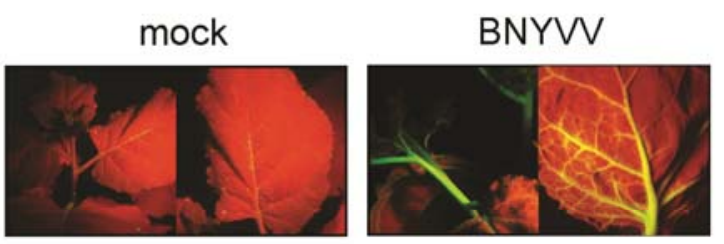

B

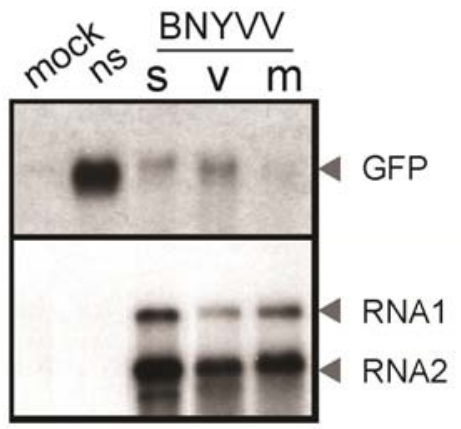

BNYVV-p14 --MGMV----DSLCVFVGRVITEGSESVEGVERFSIKF-SEWK--LFTIAVFVEYRELGE BSBMV-p14 --MEKS----NSIGVYVKDPIT------NDCRLFSVKC-GNWC--LFTNHVFVTYRGKND BdMOV-p13 --MG-------GVSIFV-----------EGDCVFSISC---------ELPVALAYWPRIN RSNV-CYSR --MSRSLLSTVNIHVLV----------DGKLVYSFAVRGPWCNGSVTNRV-VQYLP-GN * $\quad .:$ : * $\quad: .:$ *

BNYVV-p14 KECSLKDAG-------RLHFNVSCVKCCQKL-KCKKQNKNHSKHVQNGYLRKVRNFSILG BSBMV-p14 DEKVVKDTC-------RLHFHVKCVSCSSKV-TFKANNRDHLEWLSKGFVRVNRNFSIVG BdMOV-p13 YVKVCNAVCLHGQIPNSFHLGLICNECENSW-LVKVRTGLHTILVDGGFCRVANSKTVQG RSNV-CYSR STNASSASR-------ALSFRWSCIVCGSHVGDIKKYIRLHRRLLRNNYCRMQHKFTFTE

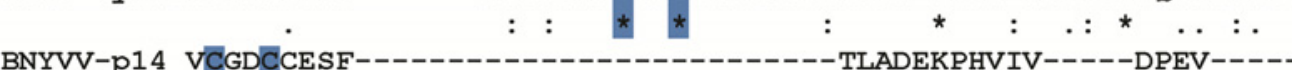
BSBMV-p14 ACSKCRGVF-----------------------DSCAQQDEL-------DNNVV---BdMOV-p13 MCYSCLGA--------------------------ESKELVTTGLFETSVKRVKLS RSNV-CYSR VCTSCMCTYGLKVPCVEAPITARPAKDGSEHVVKTEGTMDCSEVVP-----DSDTSSDSD .:

C

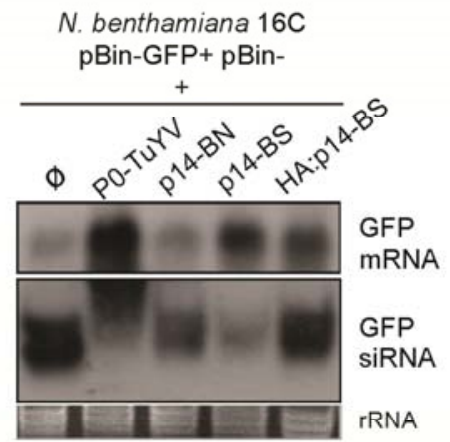

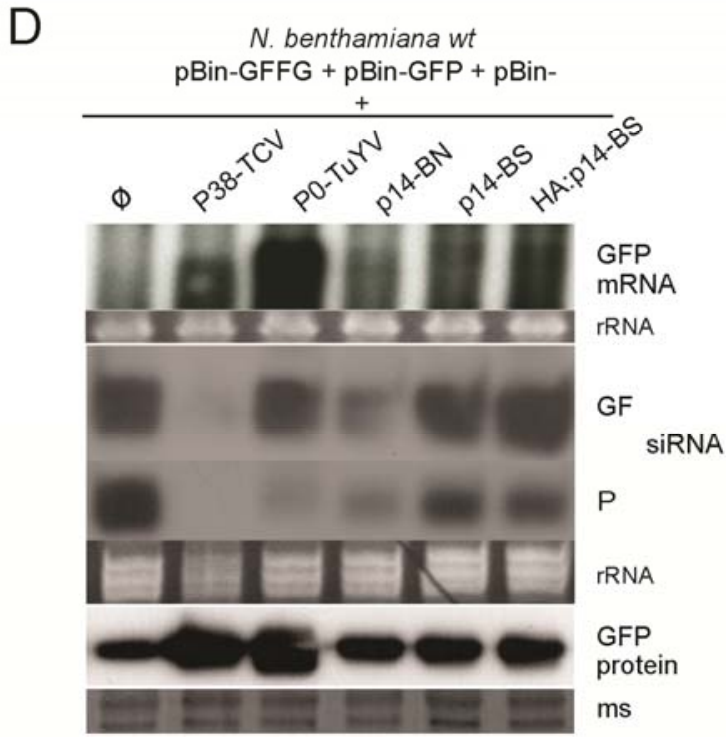

Fig. 1. Benyviruses encode cysteine-rich protein (CRP) RNA silencing suppressor. A, Viral suppression of established green fluorescent protein (GFP) mRNA silencing. GFP-expressing transgenic Nicotiana benthamiana 16C plants were agroinfiltrated with pBin-GFP to trigger RNA silencing and challenged with Beet necrotic yellow vein virus (BNYVV) infection (BNYVV, middle panel) or mock inoculated (mock, left panel). Photographs were taken 14 days postinoculation (dpi) under UV light in darkness (left and middle panels). Viral RNA1, RNA2. and GFP mRNA from infected plants were extracted from stem (s), vein (v), and mesophyll $(\mathrm{m})$ tissues and detected with specific probes (right panel). Mesophyll tissues from nonsilenced (ns) and mockinoculated silenced (mock) plants were analyzed in parallel. B, Alignment of BNYVV and Beet soil-borne mosaic virus (BSBMV) benyvirus CRP with those of Burdock mottle virus (BdMoV) and RSNV tentative members. Amino acid sequences of BNYVV-p14 (X04197), BSBMV-p14 (NC_003503), BdMoV-p13 (Dr. Hideki Kondo, personal communication), and RSNV-CysR (EU099845) were analyzed with MAFFT software (v.6). Blue boxes indicate conserved cystein residues, which are presumably required for the zinc-finger ( $\mathrm{Znf}$ ) structure (this article). Basic amino acid rich region, representing the BNYVV-p14 nucleolar localization signal detected by NoD software in the loop of the Znf, is underlined in red. C, Identification of viral suppressor of RNA silencing (VSR) activity by patch test. $N$. benthamiana $16 \mathrm{C}$ leaves were co-infiltrated with Agrobacterium spp. carrying pBin-GFP together with bacteria carrying pBin61 empty vector (Ø) or expressing Turnip yellows virus (TuYV) P0, BNYVV p14 (p14BN), or BSBMV p14 without or with an hemagglutinin A epitope (HA) tag (p14BS/HAp14BS). Northern blot analyses were conducted on high molecular (GFP mRNA) and low molecular (GFP small-interfering [si]RNA) weight RNAs extracted from infiltrated leaves using a GFP-specific RNA probe. D, Analysis of primary and secondary siRNA production. $N$. benthamiana leaves were co-infiltrated with three Agrobacterium mixtures, one carrying pBin-GFP, the second carrying pBin-GF-FG trigger, and the third carrying empty or VSR-expressing vectors. Northern blot analyses were conducted on RNAs extracted from infiltrated leaves. Primary siRNAs were detected using a specific probe corresponding to a sequence used as a trigger (GF) whereas secondary siRNA were detected with a probe specific to the $3^{\prime}$ part of the GFP messenger absent from the trigger $(\mathrm{P})$. Western blot analysis of GFP was performed in parallel. Equal loadings were checked by visualization of ethidium bromide-stained total RNAs (rRNA) or membrane staining (ms). 
A

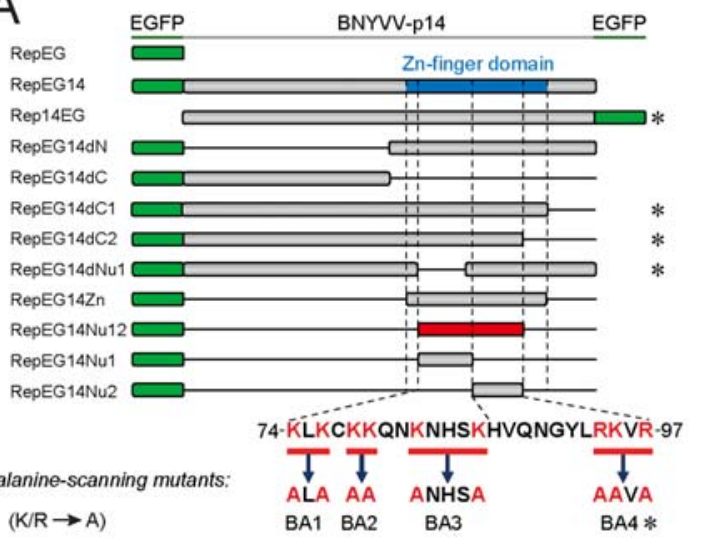

C

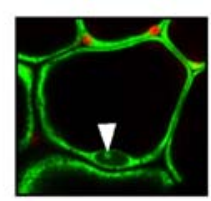

D

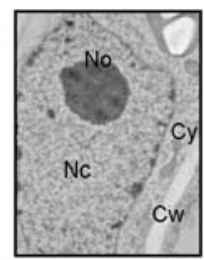

E

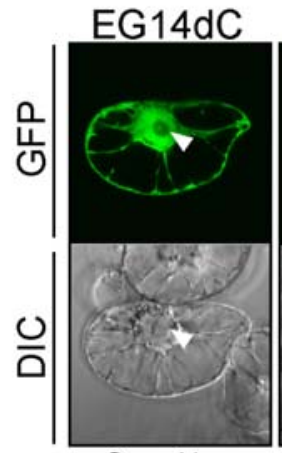

$\mathrm{Cy}+\mathrm{Nc}$

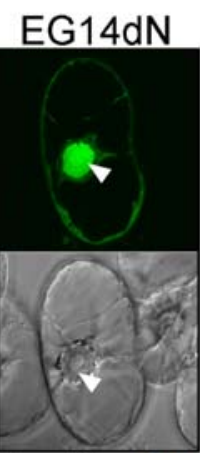

$\mathrm{Cy}+\mathrm{Nc}+\mathrm{No}$
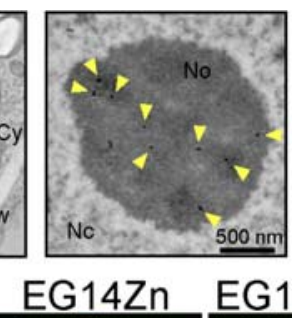

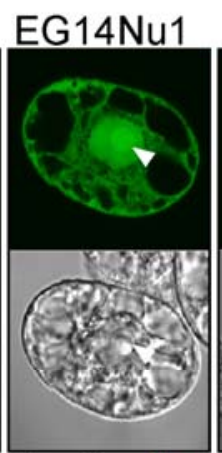

$\mathrm{Cy}+\mathrm{Nc}+\mathrm{No}$
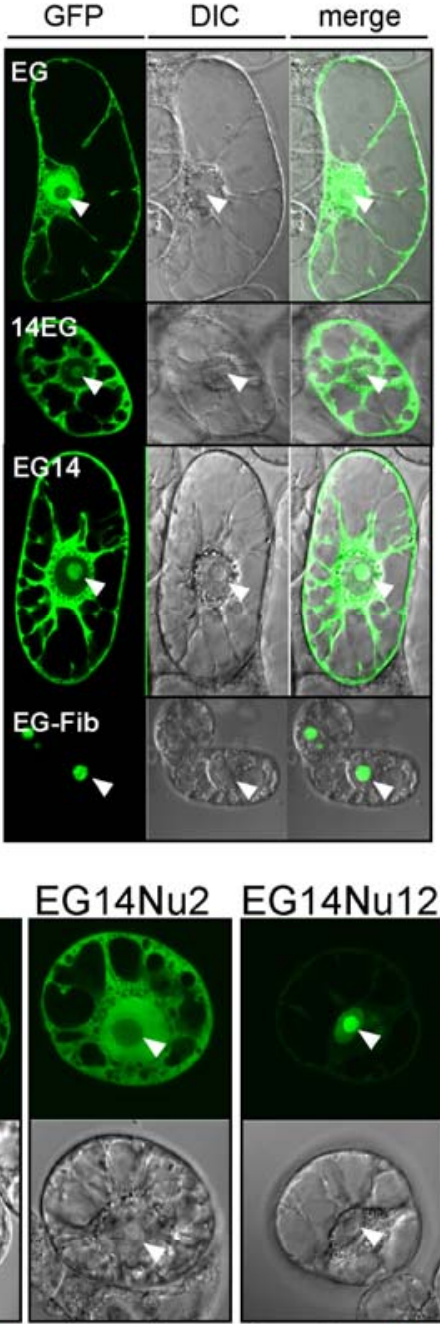

$\mathrm{Cy}+\mathrm{Nc}$

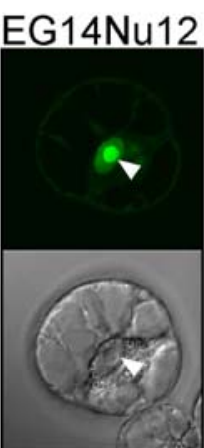

$\mathrm{Cy}+\mathrm{Nc}+\mathrm{No}$

$\mathrm{F}$
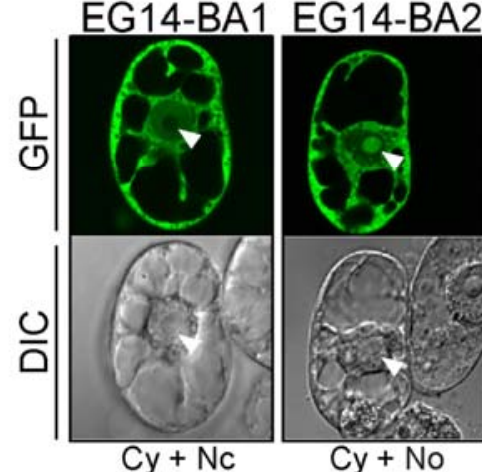

$\mathrm{Cy}+\mathrm{No}$
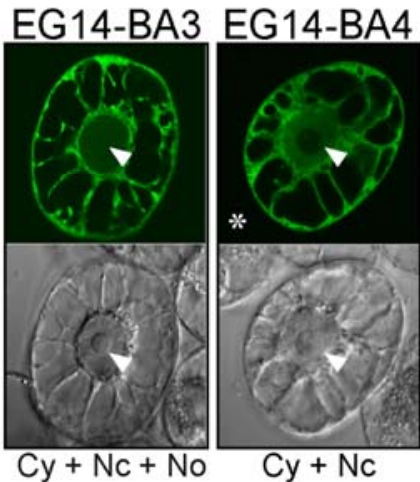

Fig. 2. Nucleolar localization signal (NoLS) is present in Beet necrotic yellow vein virus (BNYVV) p14 protein. A, Drawings of the enhanced green fluorescent protein (EGFP)-p14 fusion genes (EG14 and 14EG) cloned into the RNA3-based replicon Rep0. The green box represents the EGFP sequence whereas gray boxes correspond to the p14 sequence and its derivatives; blue and red boxes highlight the zinc-finger (Znf) domain and the basic amino acid rich sequence, respectively, displayed at the bottom of the panel (amino acids 74 to 97). The nature and the position of the mutations introduced are detailed below. Lysine or arginine residues of the NoLS were substituted with alanine residues (shown in red letters). B, Subcellular localization of EGFP (EG), p14EGFP (14EG), EGFP-p14 (EG14), and EGFP-fibrillarin fusion protein (EG-Fib) in tobacco BY-2-infected protoplasts $24 \mathrm{~h}$ after inoculation with replicon constructs supplemented with RNA1 and RNA2. GFP fluorescence was observed under confocal laser-scanning microscopy (GFP). Differential interference contrast (DIC) images of the same cells and images merged with GFP panels (merge) are presented. White arrowheads indicate the nucleolus (B, C, E, F, and G). C, EGFP-p14 protein localizes similarly in mesophyll cells. RNA1+2+repEG14 were inoculated to Chenopodium quinoa leaf and observed 7 days postinoculation. Red dots correspond to chloroplast auto fluorescence. D, Immuno-labeling of nucleolar p14 in BNYVV-infected C. quinoa leaf cell. Ultrathin sections of BNYVV-infected $C$. quinoa leaves were treated with gold-labeled anti-p14 antiserum and subjected to electron microscopic observation. Left panel displays the nucleus $(\mathrm{Nc})$ of a BNYVV-infected cell where cytoplasm $(\mathrm{Cy})$ and cell wall $(\mathrm{Cw})$ appear. In the enlarged right panel, yellow arrowheads indicate the presence of specific gold particles in the nucleolus compartment (No). E, Subcellular localization of the EGFP fused to specific domains of p14. The strong retention of EG14Nu12 fusion protein in the nucleolus demonstrates the presence of an NoLS at amino acid position 74 to 97, as shown in A. F, Point mutation analyses of NoLS p14 mutants. Lysine or arginine residues of the NoLS were replaced with alanine residues in the EG14 fusion sequence (see A). Subcellular localization profiles were analyzed as for B. Asterisks (A and F) indicate weak fluorescence of the constructs that rendered statistical analyses difficult for localization investigations. 
RNA2. Protoplasts were observed $24 \mathrm{~h}$ postinoculation (hpi) under confocal laser-scanning microscopy (CLSM), as described previously (Erhardt et al. 2000). The unfused EGFP protein expressed from the replicon was distributed in the cytoplasm and nuclear compartments without reaching the nucleolus (Fig. 2B, EG). In contrast, when p14 was fused to the C-terminus of the EGFP sequence (Fig. 2A, RepEG14), the protein accumulated in the cytoplasm where it was produced and, in addition, clearly labeled the nucleolus of the infected cells (Fig. 2B, EG14). Similar results were obtained with p14 fused to the $\mathrm{N}$ terminus of the EGFP sequence (Fig. 2A, rep14EG; and B, 14EG) but with lower fluorescence intensities. Nucleolus labeling was visualized in parallel by the use of an EGFP-fibrillarin fusion protein (Fig. 2B, EG-Fib). Nucleolar localization was also found within Chenopodium quinoa leaves infected with RNA1+2+RepEG14 (Fig. 2C) and confirmed by immuno-gold labeling of the wt p14 in the nucleolus of infected cells (Fig. 2D) which was absent in noninfected cells (data not shown). EGFP-p14 fusion was chosen for further analyses in order to maintain identical translation contexts for mutagenesis experiments and efficient detection of the fluorescent cells. Using deletion mutants of the BNYVV p14 (Fig. 2A), we were able to assign the nuclear or nucleolar targeting properties to the C-terminus part of the protein (Fig. 2E, compare EG14dN and EG14dC). Furthermore, we demonstrated the existence of an NoLS within the Znf domain (Fig. 2A, RepEG14Zn) between amino acid residues 74 and 97, because the fusion protein accumulated in the nucleus and, particularly, in the nucleolus of infected cells (Fig. 2A and E, EG14Zn and EG14Nu12). The NoLS sequence was further separated into two domains (Fig. 2A, EG14Nu1 and EG14Nu2). EG14Nu1 targeted both the nucleus and nucleolus whereas EG14Nu2 was solely addressed to the nucleus (Fig. 2E, EG14Nu1 and EG14Nu2), demonstrating the requirement of the entire $\mathrm{Nu} 12$ domain for nucleolar targeting. In this experiment, constructs labeled with an asterisk (Fig. 2A) showed either weak fluorescence or undetectable proteins in Western blotting experiments (data not shown) and, therefore, were considered with caution for data interpretation even if their localization validated our results (e.g., EG14dNu1 was not detected in the nucleolus; data not shown).

Alanine replacement of basic residues within domain 74-97 was performed to produce p14-BA1 to p14-BA4 mutants in the RepEG14 context (Fig. 2A). All constructs were detected in infected cells; however, only EG14BA2 mutant (KK $\left.{ }^{78-79} \mathrm{AA}\right)$ behaved like EG14 (compare Fig. 2B, EG14 to F, EG14BA2) whereas the EG14BA3 mutant $\left(\mathrm{K}^{82} \mathrm{~A}-\mathrm{K}^{86} \mathrm{~A}\right)$ was able to reach both the nucleus and the nucleolus; however, the fluorescence distribution appeared distinct from EG14. EG14BA1 $\left(\mathrm{K}^{74} \mathrm{~A}-\right.$ $\left.\mathrm{K}^{76} \mathrm{~A}\right)$ and EG14BA4 ( $\left.\mathrm{RK}^{94-95} \mathrm{AA}-\mathrm{R}^{97} \mathrm{~A}\right)$ mutant proteins were detected in the nucleus but no longer in the nucleolus (Fig. 2F, EG14BA1 and EG14BA4). We further analyzed the effect of single basic residue replacement on EG14 nucleolar localization. $\mathrm{K}^{70} \mathrm{~A}, \mathrm{~K}^{74} \mathrm{~A}, \mathrm{~K}^{76} \mathrm{~A}, \mathrm{R}^{94} \mathrm{~A}, \mathrm{~K}^{95} \mathrm{~A}$, and $\mathrm{K}^{97} \mathrm{~A}$ individual substitutions were introduced within EG14 and subjected to CLSM observation. Only EG14K $\mathrm{K}^{97} \mathrm{~A}$ was restricted to the cytoplasm and nucleus whereas all other single mutants behaved like wt p14 (data not shown). To limit the occurrence of reversion of such single amino-acid changes during replication cycles and to take advantages of their varied localizations, p14BA1 to p14BA4 were chosen for subsequent analyses. New analyses were performed in an RNA $2 \Delta \mathrm{p} 14$ background and gave the same localizations as those obtained in the presence of $\mathrm{wt}$ RNA2 (data not shown). Because no relocalization of the mutants was observed in the presence of wt p14 in protoplast infections, we concluded that the localizations of EGFPp14BA1 to p14BA4 are intrinsic to the proteins.

\section{BNYVV p14 nucleolus targeting requires} a functional Znf domain.

Because the NoLS is embedded in the putative Znf domain, an alanine scanning of the BNYVV p14 cysteine residues (C/A) was conducted. Nine single mutants $\left(\mathrm{C}^{8} \mathrm{~A}, \mathrm{C}^{54} \mathrm{~A}, \mathrm{C}^{68} \mathrm{~A}\right.$, $\mathrm{C}^{71} \mathrm{~A}, \mathrm{C}^{72} \mathrm{~A}, \mathrm{C}^{77} \mathrm{~A}, \mathrm{C}^{105} \mathrm{~A}, \mathrm{C}^{108} \mathrm{~A}$, and $\mathrm{C}^{109} \mathrm{~A}$ ) were fused to EGFP in the RepEG14 context (Fig. 3A). Protoplasts were infected with wt RNA1 and RNA2 supplemented with the different RepEG14(C/A) mutants. EG14C ${ }^{8} \mathrm{~A}, \mathrm{EG} 14 \mathrm{C}^{54} \mathrm{~A}, \mathrm{EG} 14 \mathrm{C}^{72} \mathrm{~A}$, EG14 $\mathrm{C}^{77} \mathrm{~A}$, and $\mathrm{EG} 14 \mathrm{C}^{109} \mathrm{~A}$ mutants behaved like EG14, localizing to the cytoplasm and the nucleolus of the infected cells (Fig. 3B). Conversely, EG14C ${ }^{68} \mathrm{~A}, \mathrm{EG} 14 \mathrm{C}^{71} \mathrm{~A}, \mathrm{EG} 14 \mathrm{C}^{105} \mathrm{~A}$, and EG14C ${ }^{108} \mathrm{~A}$ mutants lost their nucleolus targeting and showed weak fluorescence (Fig. 3B, asterisk in the corner of the picture). The same transcript combinations were rub inoculated to C. quinoa leaves. Chlorotic local lesions appeared 7 days dpi and viral components were analyzed (Fig. 3C) using Western blot (WB) and Northern blot (NB). No significant difference in viral RNA accumulation was observed (Fig. 3C, NB) and RNA2-encoded coat protein (CP) and wt p14 accumulations were comparable with the control (Fig. 3C, WB, middle and lower panels). In contrast, only EG14 mutant proteins that were still able to enter the nucleolus were easily detected on WB whereas mutants EG14C ${ }^{68} \mathrm{~A}, \mathrm{EG} 14 \mathrm{C}^{71} \mathrm{~A}, \mathrm{EG} 14 \mathrm{C}^{105} \mathrm{~A}$, and EG14C ${ }^{108} \mathrm{~A}$ were almost undetectable (Fig. 3C, WB).

In order to test the functionality of the above C/A substitution mutants, in vitro transcripts of each mutant were inoculated together with RNA1 and RNA2 $2 \Delta \mathrm{p} 14$ on $C$. quinoa leaves. After 7 days, small necrotic lesions appeared on leaves inoculated with RNA1+2- $\Delta \mathrm{p} 14$ alone. Chlorotic fluorescent local spots were observed when wt EG14 or one of the five $\mathrm{C} / \mathrm{A}$ mutant proteins that were still able to reach the nucleolus was expressed from the replicon RNA (data not shown), indicating their functional VSR activity (Guilley et al. 2009; Kozlowska-Makulska et al. 2010). NB and WB analyses were performed on infected tissues and the results confirmed the effective complementation provided by the EG14 proteins, with a slightly lower efficiency observed for EG14C ${ }^{54} \mathrm{~A}$. None of the mutants affected at cysteine residues $68,71,105$, and 108 was able to complement RNA2 $\Delta$ p14 and failed to form local lesions due to the lack of a functional VSR, as indicated by the absence of viral amplification detection (Fig. 3D).

\section{Nucleolar localization is not essential for silencing suppression, but intact NoLS is required for protein stability and VSR efficiency.}

Having demonstrated the essential role of the Znf for both the nucleolar addressing and the stability of the p14 protein, we checked whether the basic rich residues of the NoLS sequence were involved in the VSR activity of the protein. For this purpose, NoLS mutants were expressed in the viral context either by replacing the RNA2 p14 sequence with the mutated sequence or by providing the mutated sequence in fusion or not with the EGFP sequence via a replicon vector. When RNA1 and RNA2 mutants were inoculated to protoplasts, 1+2BA3 RNAs accumulation was comparable with that of the wt, with a decrease of RNA1 amount, whereas other RNA2 mutants were replicated but accumulated at higher levels than the p14-defective mutant (Fig. 4A, compare RNA2 accumulation and rRNA load). When the same transcript combinations were inoculated onto $C$. quinoa leaves, only RNA2-BA1, RNA2$\mathrm{BA} 2$, and RNA2-BA3 mutants induced the formation of chlorotic local lesions at a necrotic center 7 days postinoculation (dpi) (Fig. 4B, bottom lane, phenotype Cn). Conversely, RNA2 $\Delta$ p14 and RNA2-BA4 mutants induced small necrotic lesions (Fig. 4B, phenotype Sn) in which viral RNAs and proteins were below the limit of detection (Fig. 4B, left panel, NB 


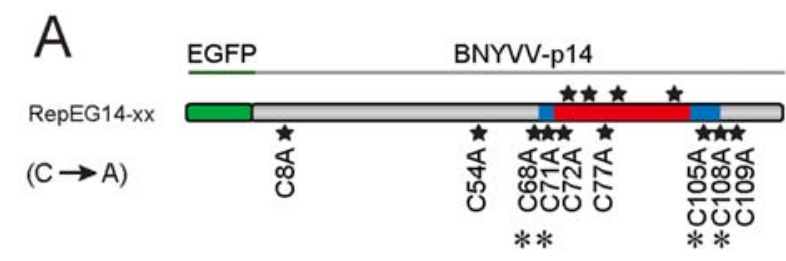

B EG14

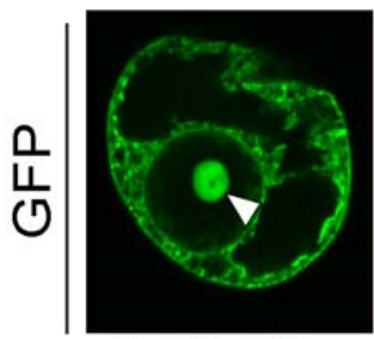

$\mathrm{Cy}+\mathrm{Nc}+\mathrm{No}$

C72A

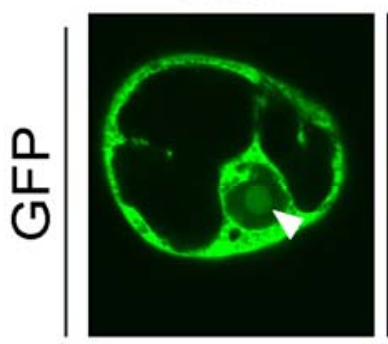

$\mathrm{Cy}+\mathrm{Nc}+\mathrm{No}$
C8A

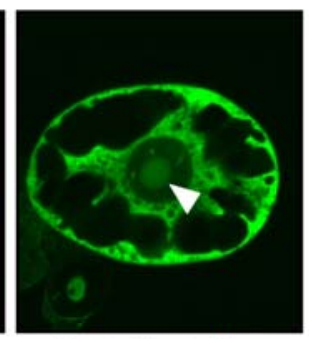

$\mathrm{Cy}+\mathrm{Nc}+\mathrm{No}_{0}$

C77A

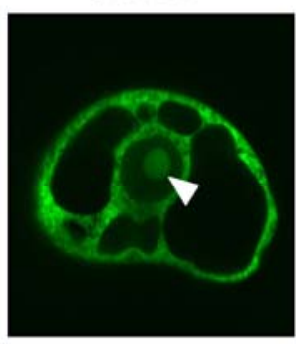

$\mathrm{Cy}+\mathrm{Nc}+\mathrm{No}$
C54A

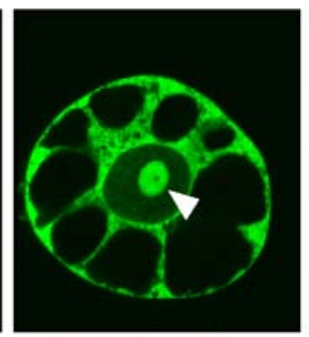

$\mathrm{Cy}+\mathrm{Nc}+\mathrm{No}$

C105A

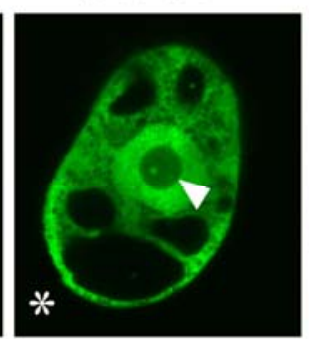

$\mathrm{Cy}+\mathrm{Nc}$
C68A

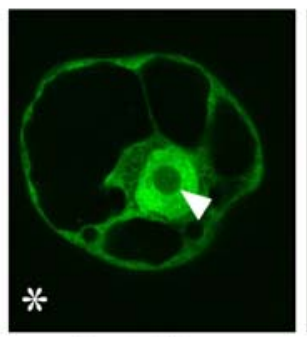

$\mathrm{Cy}+\mathrm{Nc}$

C108A

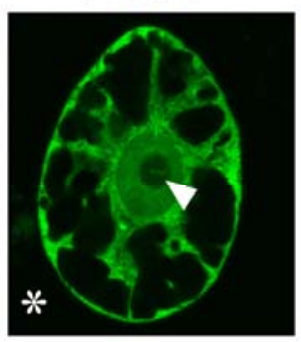

$\mathrm{Cy}+\mathrm{Nc}$
C71A

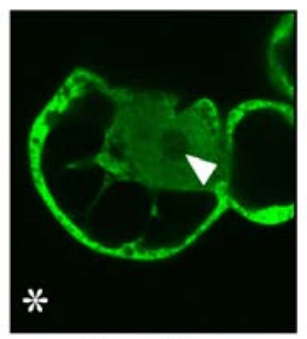

$\mathrm{Cy}+\mathrm{Nc}$

C109A

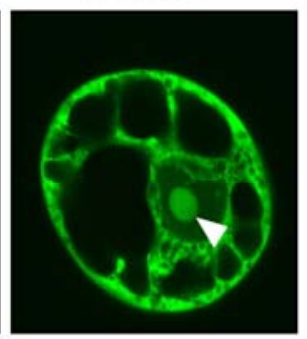

$\mathrm{Cy}+\mathrm{Nc}+\mathrm{No}$
C

c. quino

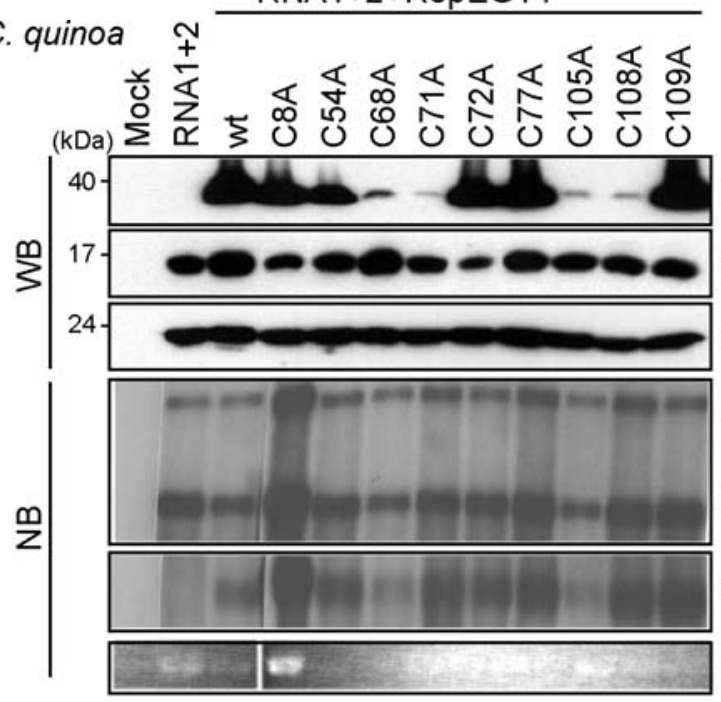

RNA1+2+RepEG14

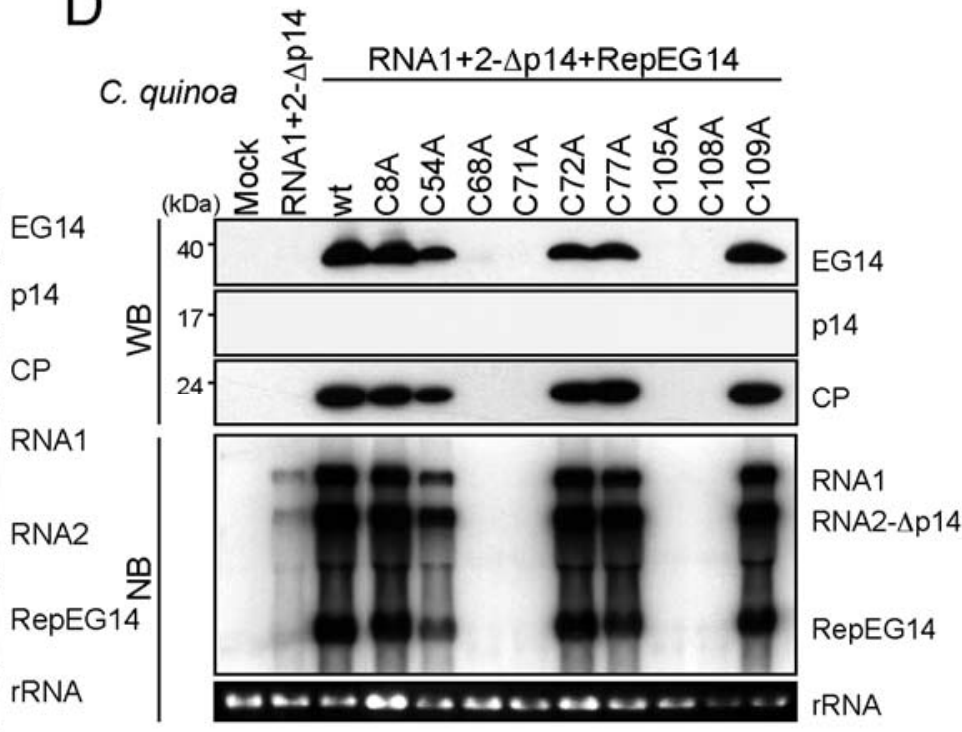

Fig. 3. Identification of the essential cysteine residues for p14 zinc-finger (Znf) folding. A, Drawings of the enhanced green fluorescent protein (EGFP)-p14 fusion genes. The green box represents the EGFP sequence whereas gray boxes correspond to the p14 sequence; blue and red boxes highlight the Znf domain and the nucleolar localization signal, respectively. The nature and the position of the mutations introduced are detailed. The nine cysteine residues were independently mutated into alanine in the EG14 fusion sequence and their position is indicated by stars. B, Four out of nine cysteine residues are essential for p14 stability and its proper localization. GFP fluorescence was observed under confocal laser-scanning microscopy (GFP). Asterisks indicate weak fluorescence of the constructs (also highlighted on A) that lost their nucleolar localization. C, Molecular analyses of C/A substitution mutant fate in the viral context. In vitro transcripts of RepEG14 were inoculated to Chenopodium quinoa leaves together with RNA1 and RNA2. Total proteins and RNAs were extracted from local lesions. The coat protein (CP), p14 protein, and EGFP-p14 fusion protein (EG14) were specifically immunodetected by Western blotting (upper panels). Viral RNA1 and -2 and replicon EG14 were detected using specific antisense riboprobes (lower panels). Ethidium bromide staining of rRNA estimated loading of the gel. D, Molecular analyses of C/A substitution mutant fate in the absence of wild-type (wt) p14. In vitro transcripts of RepEG14 variants were inoculated to C. quinoa leaves together with RNA1 and RNA2Ap14 and analyzed as in C. 


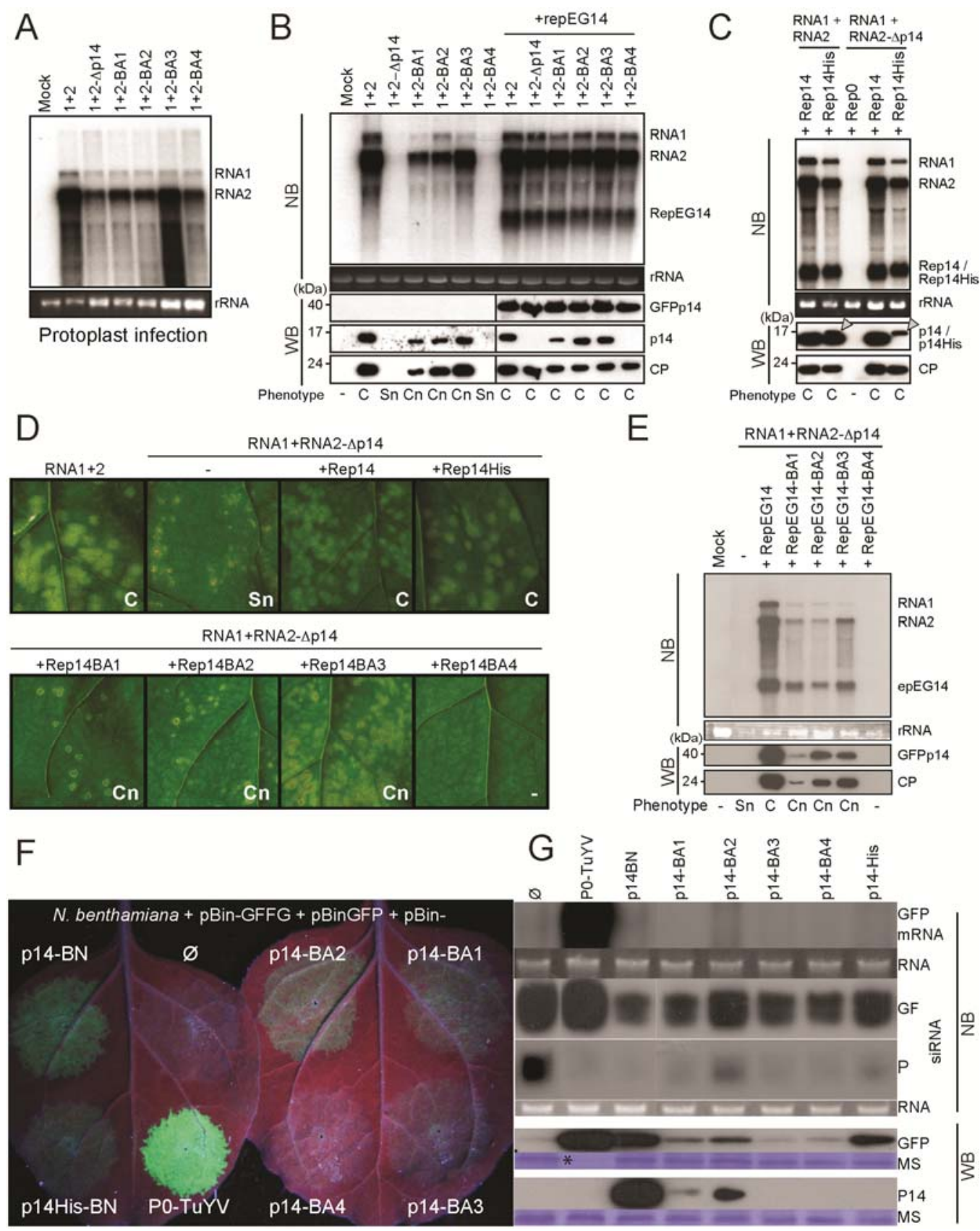

Fig. 4. Viability of p14 nucleolar localization signal (NoLS) mutant viruses and viral suppressor of RNA silencing (VSR) activity. A, Replication of NoLS mutants at the single-cell level. Chenopodium quinoa protoplasts were infected with Beet necrotic yellow vein virus (BNYVV) RNA1 and p14-NoLSmutated RNA2. RNAs extracted $24 \mathrm{~h}$ postinoculation were subjected to Northern blot analysis using BNYVV-specific RNA probes. B, Virus accumulation in local lesions on $C$. quinoa leaves. RNA1 and RNA2 variants (wild type [wt]: 2; p14 defective: 2- $\Delta$ p14; p14-NoLS mutants: 2-BA1 to 2-BA4) were inoculated to C. quinoa leaves alone or in the presence of RepEG14. Observed phenotypes of local lesions 7 days postinoculation (dpi) that were harvested are detailed at the bottom of the panels (C: chlorotic lesion; Cn: C with necrosis in the center; Sn: small necrotic lesion; -: no symptom; see D for pictures). Northern analysis was conducted using BNYVV specific riboprobes. Western blot analyses of enhanced green fluorescent protein (EGFP)-p14, p14, and coat protein $(\mathrm{CP})$ in the infected foci are presented. C, A 10-fold less accumulation of histidine-tagged p14 (p14His) was sufficient to provide VSR function. In vitro synthesized RNA1 and RNA2 or RNA2- $\Delta$ p14, with or without a replicon carrying p14His ${ }_{6}$-tagged protein sequence (Rep14His), were inoculated to $C$. quinoa leaves. Total RNA and protein samples were analyzed as for B. Arrows indicate the size-elevated position of the His 6 -tagged p14 protein. D, Complementation of p14-defective BNYVV with replicon expressing NoLS mutants. Comparative analysis of the C. quinoa local lesion phenotypes obtained 7 dpi with wt RNA1+2, RNA1+2 $\mathrm{p} 14$ alone, or supplemented with replicon carrying wt-p14, His-tagged, or NoLS-mutated variants. A chlorotic local lesion phenotype implies complete complementation while $\mathrm{Cn}$ represents partial complementation of p14 deficient function. E, The p14 protein properties are not influenced by fusion with the EGFP sequence. Viral RNA and protein accumulation levels were analyzed 7 dpi from $C$. quinoa local lesions infected by RNA1 $+2 \Delta$ p14 supplemented with RepEG14 or NoLS mutants. P14 mutants behaved similarly when fused or not to EGFP. All RNA and protein species are specified on the right of each panel. F, Mutations within NoLS affect VSR activity. Nicotiana benthamiana leaves were infiltrated with Agrobacterium spp. containing the GFP gene and GF-FG trigger together with empty binary vector (Ø) or binary vector expressing the VSR (p14-BN, p14His-BN, P0- Turnip yellows virus [TuYV], and p14BA mutants). Leaves were photographed under UV light 4 days postinfiltratino. G, Molecular analyses of GFP mRNA and primary and secondary small-interfering (si)RNAs within the patched areas. Experiments were conducted as in Figure 1D. Primary siRNAs were detected using a specific probe corresponding to sequence used as a trigger (GF) whereas secondary siRNAs were detected with a probe specific to the $3^{\prime}$ part of the GFP messenger absent from the trigger (P). Western blot analyses of GFP and p14 protein were performed in parallel using specific antibodies. Equal loading was checked by visualization of ethidium-bromide-stained total RNAs (rRNA) or membrane staining (ms), except for the P0-TuYV sample, which was subjected to a one-fifth dilution for GFP detection and is labeled with an asterisk. 
and WB). Viral RNA1 and RNA2 as well as CP and p14 proteins were detected from 1+2-BA1-, 1+2-BA2-, and 1+2-BA3inoculated samples, hence confirming the efficient viral amplification provided by the attenuated VSR activity of p14-NoLS mutants. The accumulations of viral RNAs and proteins were lower than that of the wt (Fig. 4B, left). This was not due to a cis effect of the mutations present on p14 open reading frame because all mutants were efficiently amplified when they were supplemented with a RepEG14 (Fig. 4B, right panel). In the presence of EG14 protein, the necrotic center disappeared, giving rise to full chlorotic lesions and RNA accumulation was restored in the infection foci (Fig. 4B, right). Here again, WB evidenced the instability of the p14BA4 mutant and a lower stability of p14BA1 protein as compared with wt (Fig. 4B, right, WB).

To distinguish between the effect of the NoLS mutation per se and p14 stability in VSR function, we used a C-terminal histidine-tagged p14 (p14His), which was functionally active in silencing suppression in patch test experiments (discussed below). p14His accumulated approximately 10-fold lower than the wt p14 but still efficiently complemented the p14-defective virus on $C$. quinoa leaves (Fig. $4 \mathrm{C}, \mathrm{CP}$ levels; and D, chlorotic spots). Interestingly, when the empty replicon vector (Rep0) was added to inoculums deficient in p14 synthesis, no lesion appeared on the leaves (Fig. 4, compare B, $1+2-\Delta$ p14 and C, $1+2-\Delta$ p14 + Rep0), indicating a defective interfering effect of the viral vector in the absence of a functional VSR, a feature observed previously for Znf-deficient p14 mutants (Fig. 3D). To further benefit from this effect, BNYVV RNA1+2- $\Delta$ p14 in vitro transcripts were inoculated on $C$. quinoa leaves together with replicon vectors expressing wt or mutated p14 proteins. Local lesions clearly appeared on the leaves 7 dpi (Fig. 4D) when p14-BA1, p14-BA2, and p14-BA3 proteins were expressed, indicating that these p14 mutants were able to complement RNA2 $\Delta \mathrm{p} 14$. The complementation was more efficient for the BA3 mutant, because larger local lesions with a small necrotic center appeared, than for BA1 and BA2, because smaller chlorotic lesions were produced and harbored a necrotic center. The same results were obtained with EG14 protein expressed via the replicon because higher viral RNA amounts were found for BA1 and BA3 compared with BA2 (Fig. 4E, NB, compare RNA2, repEG14, and rRNA loads). Again, $\mathrm{CP}$ accumulation in BA1 was lower than in BA2 and BA3 (Fig. 4E, WB), as previously observed (Fig. 4B). This suggested that EG14 protein behaves similarly to p14 proteins in terms of complementation, symptom expression, and protein stability; these properties also apply for fused and nonfused mutants. Taken together, the partial complementation of the p14-defective virus provided by p14-BA1 to p14-BA3 supports an effect of the introduced mutations per se on the VSR activity.

To support these observations, the four NoLS mutants p14BA1 to p14-BA4 were expressed via Agrobacterium tumefaciens in $N$. benthamiana $16 \mathrm{C}$ plants, as described before. The resulting fluorescence was comparable among the p14 mutants, rendering the interpretation difficult (Supplementary Fig. S1). Interestingly, when the same experiment was monitored 4 days postinfiltration in wt $N$. benthamiana in the presence of the pBin-GFP and the GF-FG-silencing trigger, a silencing suppression of the GFP comparable with p14His was detected for BA1 and BA2 mutants (Fig. 4F). No fluorescence was noticed for BA3 and BA4 mutants (Fig. 4F). NB detection patterns of GFP mRNA and siRNAs and protein content analyses were conducted on equally loaded RNAs and proteins (Fig. $4 \mathrm{G})$. The obtained data confirmed the results presented in Figure 1 for TuYV-P0 and p14-BN. Immunodetection of the GFP within the patches reflected the low fluorescence observed for
p14-BA1 and p14-BA2 mutants. Unexpectedly, GFP mRNA detection was poor for all samples expressing BNYVV VSR variants, thus rendering the silencing-suppression interpretations difficult in regard to fluorescence intensities. We noticed, however, that GFP protein levels were related to the detection level of the p14 proteins, except for p14His, which was not detected in the patches (Fig. 4G, WB). Finally, we were unable to correlate the accumulation of the GFP protein to lowered siRNAs accumulation except for wt p14. Surprisingly, the GF and P siRNA accumulations for p14-BA1, p14-BA3, and p14BA4 were comparable with those of wt p14 in the patches (Fig. 4G, NB). Conversely, the p14His effect was comparable with p14-BA2 in term of siRNAs outcome, suggesting lower VSR effects as higher levels of siRNA were monitored (Fig. $4 G)$, and $P$ secondary siRNAs were detected for BA2 and p14His samples. The function of wt p14 appeared comparable between viral and patch experiments. However, the mutations introduced in the NoLS affected properties of p14 that apparently were not linked directly to its VSR activity per se; in particular, p14-BA3, which provided a significant complementation in the viral context but was unable to suppress the silencing of the GFP in the patches, suggesting its stabilization by another viral component.

\section{P14 CRP self-interact.}

When BNYVV p14 protein was produced in infected $C$. quinoa plants and was analyzed by WB using BNYVV-p14specific antibodies, high molecular weight proteins corresponding to twice the size of the protein were detected. Because such a signal was not always retrieved, we performed sodium dodecyl sulfate polyacrylamide gel electrophoresis (SDSPAGE) followed by Western blotting of total proteins from infected tissues that were heat denatured at $95^{\circ} \mathrm{C}$ for 0 to 120 min. In such conditions, the $\mathrm{CP}$ was detected in all samples (Fig. 5A, CP) whereas p14 amounts decreased in relation to the time of heat denaturation and had completely disappeared after 30 min of heating (Fig. 5A, p14). A band corresponding to the expected dimer form of $\mathrm{p} 14$ protein was detected in nonheated samples and at a lower level in the 2-min-treated samples but disappeared after extended treatments (Fig. 5A, p14dimer). To confirm the existence of p14 self-interaction, we used the yeast two-hybrid system.

The wt p14 and NoLS mutants were fused to the DNA binding domain (BD) and activating domain (AD) of the GAL4 transcription factor in pGBKT7 and pGADT7 vectors, respectively. Yeast strains AH109 and Y187 were transformed with recombinant plasmids. After selection and mating, diploids were selected on SD-WL minimal media. Yeasts carrying vectors were then plated onto SD-WLH and analyzed for the expression of the BD-p14 and AD-p14 fusion proteins (Fig. 5B, upper panel). All p14 proteins were detected in both fusion forms, with the exception of $\triangle \mathrm{NoLS}$ and BA2 mutants detected only in fusion with $\mathrm{AD}$ and $\mathrm{BD}$, respectively (Fig. 5B, lower panel). Nevertheless, when yeast diploids were plated onto SD-WLH, the His3 gene expression revealed p14 and p14BA2 self-interactions as well as p14 and p14BA2 interactions and, thus, the presence of AD-BA2 protein expression. A slower growth suggested weaker interactions between wt p14 and p14BA3 and between p14BA2 and p14BA3. BSBMV-p14 (p14BS) self-interaction was analyzed in the same way. Yeasts were transformed with the BD- and AD-p14BS fusion constructs and selected on SD-WL media, then challenged for His3 gene expression (Fig. 5C, left panel). As for BNYVV, BSBMV p14 was interacting with itself (Fig. 5C, -WLH). However, although both proteins possess comparable domains (Fig. 1B), they were unable to interact with each other. The same results were obtained regardless of the yeast strains used. 
To confirm p14BS self-interaction, FRET-FLIM experiments were designed. First, the subcellular localization of p14BS was determined under CLSM using tobacco BY-2 cells transfected with pCK plasmids expressing the p14BS sequence fused to EGFP (Fig. 5D, pCK-GFPp14BS), monomeric red fluorescent protein (mRFP) (Fig. 5D, pCK-RFPp14BS), or both (Fig. 5D, upper panel). As for BNYVV CRP, BSBMV p14 was present in the cytoplasm and the nucleolus even though no NoLS was predicted with NoD algorithm. Cells expressing both p14BS fusion proteins or the EGFP and RFP-
p14BS (not shown) were analyzed by FRET-FLIM. A FRET efficiency of $9.25 \pm 2$ (12 cells measured) was obtained, indicating an interaction between the EGFP-p14BS donor and the RFP-p14BS acceptor.

\section{P14 is necessary for long-distance movement.}

Previous reports demonstrated cell-to-cell movement and VSR complementation of BNYVV by TMV movement protein (Lauber et al. 1998) and unrelated viral VSR (Guilley et al. 2009; Kozlowska-Makulska et al. 2010), indicating that p14

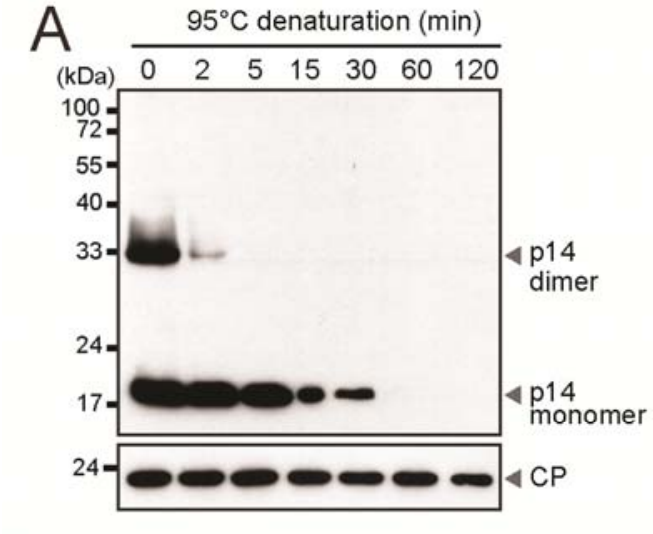

C
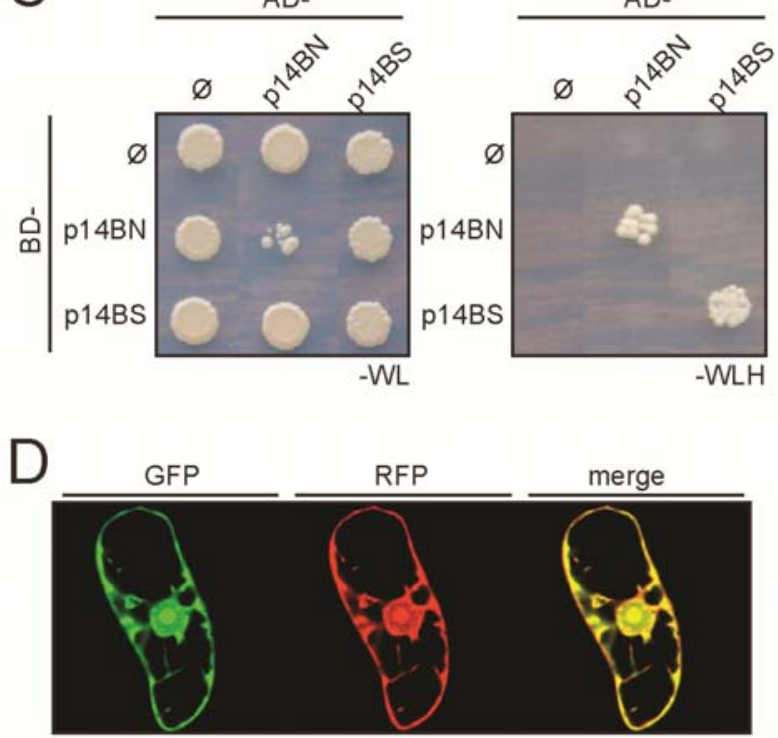

pCK-GFPp14BS + pCK-RFPp14BS
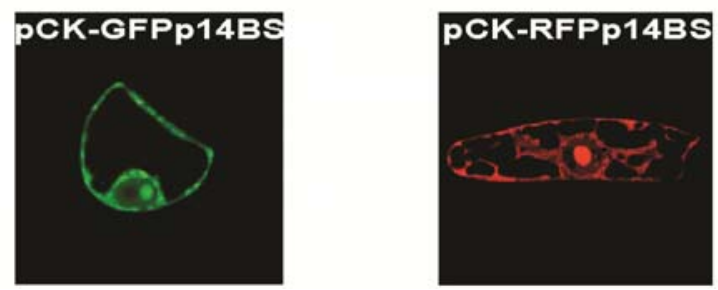
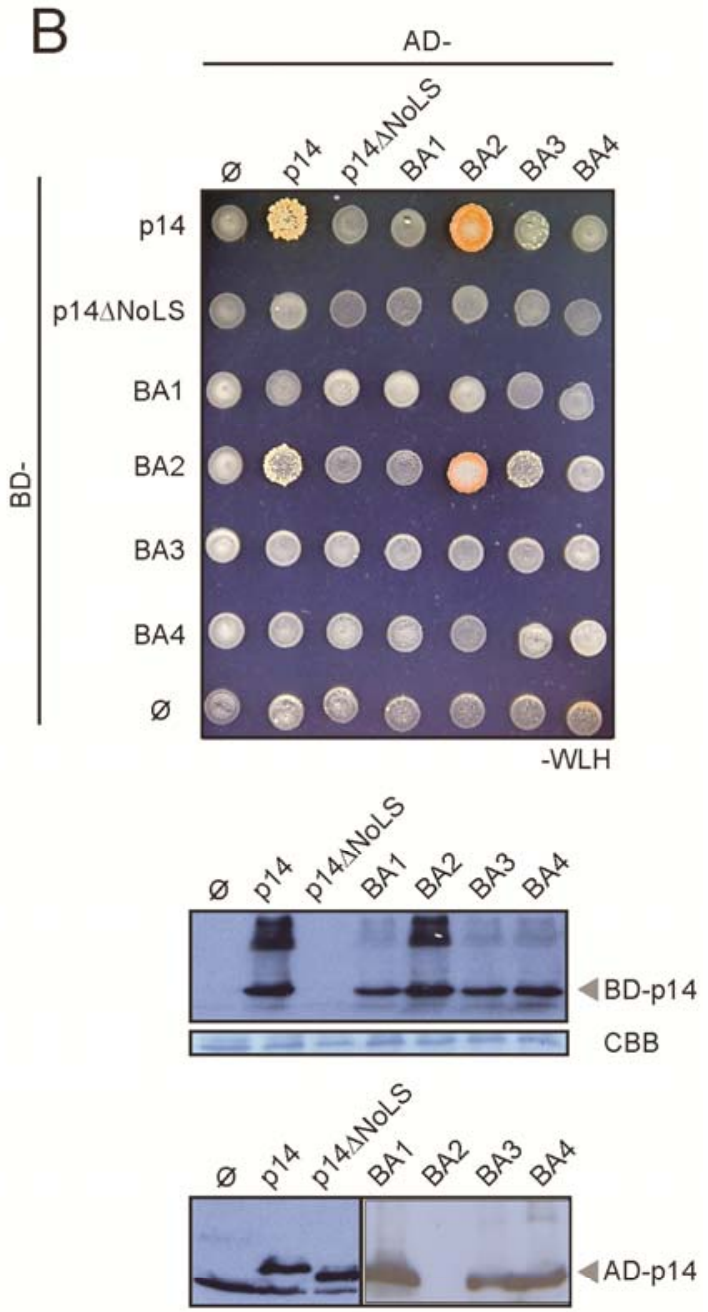

Fig. 5. Benyvirus cysteine-rich proteins (CRP) form dimers. A, Visualization of the thermosensitivity of p14 dimers by Western blotting of total protein extracts of Chenopodium quinoa local lesions infected by Beet necrotic yellow vein virus (BNYVV). Samples were heat treated at $95^{\circ} \mathrm{C}$ from 0 to 120 min. Bands corresponding to p14 and coat protein (CP) were detected by specific antisera. P14 monomer and dimer positions are indicated. Protein-protein interaction studies using B, yeast two-hybrid BNYVV p14 and nucleolar localization signal mutants or C, BNYVV and Beet soil-borne mosaic virus (BSBMV) p14 proteins were expressed in yeast as fusion proteins with the binding domain (BD) and activation domain (AD) of the GAL4 transcription factor. Selected recombinant yeast clones were grown on SD-WL media and then transferred onto selective SD minimal media (-WLH) to test for interaction. Expression of the fusion proteins in yeast cells was confirmed by Western analyses (B, lower panel). D, Subcellular localization of the BSBMV p14. Tobacco BY-2 cells were bombarded with pCK-EGFPp14BS, pCK-mRFPp14BS (lower panels), or both constructs (upper panel) to transiently express fusion proteins. FRETFLIM interaction analyses were conducted on such co-transfected cells. 
protein does not participate directly in the replication and cellto-cell movement per se. Transcripts of RNA2 constructs carrying NoLS mutations (RNA2-BA1 to RNA2-BA4) were inoculated together with RNA1 to $N$. benthamiana plants and tested for systemic spread. The wt RNA1+2 induced a systemic infection on $N$. benthamiana 2 weeks after inoculation, as shown by viral RNA accumulation in the upper leaves (Figs. 1A and 6A). When the NoLS mutants were inoculated, only RNA2BA1 and RNA2-BA3 were able to systemically spread in the upper leaves but the p14-BA1-expressing virus accumulated less efficiently than the wt and BA3 virus (Fig. 6A). Former tests in $C$. quinoa leaves showed that BA4 but not BA2 was unable to accumulate (Fig. 4B, left panel). WB analysis did not allow the detection of BA4 virus in the inoculated leaves of $N$. benthamiana (not shown). When a similar experiment was performed in Beta macrocarpa in the presence of RNA3 required for long-distance movement (Peltier et al. 2012), only the wt and BA3 mutant induced systemic symptoms (Fig. 6B) and accumulated in systemic leaves (data not shown). In this host, BA1 and BA2 were unable to move systemically. Sequencing of viral progeny in both hosts did not reveal any reversion of the introduced mutations. These results clearly illustrate the important role of BNYVV p14 in the long-distance movement of the virus.

\section{DISCUSSION}

BNYVV p14 VSR activity was demonstrated by distinct approaches (Andika et al. 2012; Dunoyer et al. 2002; Guilley et al. 2009; Kozlowska-Makulska et al. 2010; Zhang et al. 2005) and confirmed by this study. This protein acts on the silencing establishment and with a lower efficiency on established silencing in mesophyll tissues (Fig. 1A). This effect could be linked to benyvirus behavior during natural infection of sugar beet. Indeed, BNYVV infection occurs in the roots and rarely reaches the upper parts of the plant. Observation that p14 silencing-suppression activity is more efficient in roots than in leaves (Andika et al. 2005, 2012) and more efficient in vascu- lar tissues than in mesophyll tissues is in agreement with such a trait. It is not yet known whether such tissue restriction is linked to a modulated mechanism of the p14 protein itself or to one of its as-yet-unknown partners. Because similar RNAsilencing-suppression patterns were obtained with BNYVV-p14 expressed in PVX vector (Zhang et al. 2005), the involvement of a cellular factor rather than a BNYVV product is suspected. CRP-mediated silencing-suppression activity of BNYVV was weaker than PCV p15 VSR in the viral context, which was further confirmed by the patch tests (Fig. 1) (Dunoyer et al. 2002). In an agroinfiltration test, p14 VSR activities reached a maximum at 4 days and then decreased along with p14 accumulation due to an as-yet-unknown phenomenon. Globally, the benyvirus p14 VSR were less efficient than the other VSR tested in this study. This trend was also found in the accumulation levels of 21- to 24-nucleotide siRNAs, the hallmark of a fully functional silencing pathway. In $N$. benthamiana $16 \mathrm{C}$ plants, benyvirus p14 proteins appear to be acting in an overall stabilization effect of GFP mRNA within 4 days without drastically affecting siRNA production when compared with the TuYV P0 protein, which targets ARGONAUTE 1 protein (Bortolamiol et al. 2007) and induces a strong reduction of the secondary siRNAs. Benyvirus p14 proteins were able to reduce the accumulation of $\mathrm{P}$ siRNAs and, consequently, reduced the amount of GF siRNA production. The intimate action mechanism is unknown but probably differs from the TCV VSR known to inhibit indirectly DCL4 mediated production of siRNAs (Azevedo et al. 2010; Deleris et al. 2006). Because secondary siRNAs were detected in reduced amounts, we concluded that p14 VSR act downstream of the dicer activity, probably by an interference with AGO-siRNA loading. Globally, these results are in agreement with a previous report (Zhang et al. 2005) that describes the mild effect of BNYVV p14 on the initiation of PTGS and its comparison with the nucleolar-targeted CMV 2b VSR (Diaz-Pendon and Ding 2008; Gonzalez et al. 2010). CMV 2b was recently shown to be implicated in both the inhibition of PTGS and RNAdirected DNA methylation by the sequestration of siRNAs and

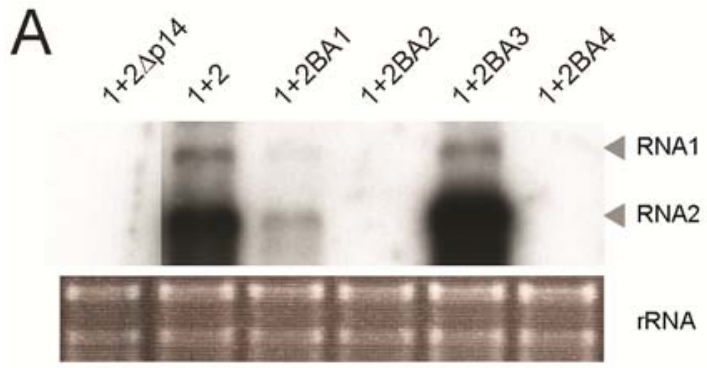

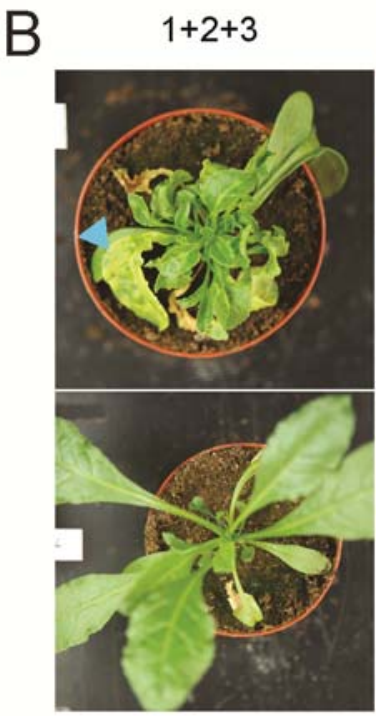

$1+2 \mathrm{BA} 2+3$

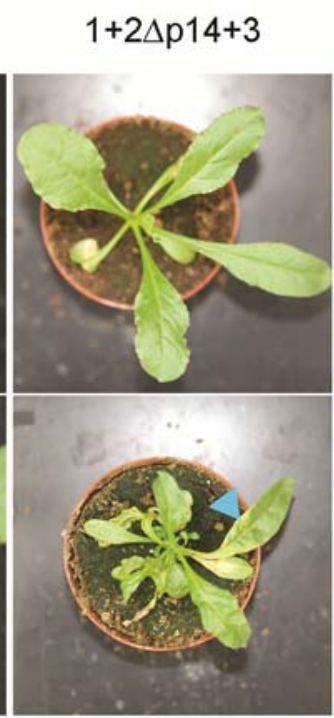

$1+2 \mathrm{BA} 3+3$

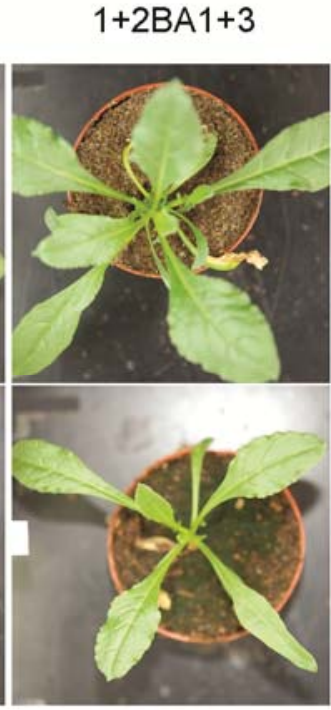

$1+2 \mathrm{BA} 4+3$

Fig. 6. Silencing-suppression deficiency affects long-distance movement of Beet necrotic yellow vein virus (BNYVV). A, Long-distance movement of BNYVV p14-nucleolar localization signal (NoLS) mutants in Nicotiana benthamiana. Plants were infected with in vitro transcripts of RNA1 supplemented with wild-type (wt) RNA2 or its p14-NoLS-mutated variants. Noninoculated upper leaves were harvested 15 days postinoculation (dpi) and analyzed by Northern blot using RNA1- and RNA2-specific riboprobes. Loading of RNA samples on the gel is visualized with ethidium bromide staining (rRNA) and the positions of viral RNA species are indicated on the right. B, Long-distance movement of BNYVV mutants in Beta macrocarpa. Seedlings were inoculated with the same RNA1+2 combinations as shown in A but supplemented with the RNA3 species essential for long-distance movement in this host. Plants were photographed $15 \mathrm{dpi}$. Yellowing symptoms (blue arrowheads) indicate systemic infection of wt and p14BA3 mutant viruses. 
dsRNA precursors (Duan et al. 2012), an siRNA binding by CMV 2b also demonstrated by Gonzalez and associates (2012). Transgene transcriptional gene silencing inhibition by CMV $2 \mathrm{~b}$ (Duan et al. 2012) is a property that was also proposed for BNYVV p14 protein (Zhang et al. 2005).

By focusing on the CRP and its expression in the viral context, we demonstrated the cytoplasmic and nucleolus localization of the benyvirus p14 proteins (Figs. 2B and D and 6D). Mutagenesis of basic residues confirmed the presence of the NoLS in BNYVV p14, as predicted by NoD (Scott et al. 2011), and precisely positioned it between amino acids 74 and 97 . The existence of a nonpredicted NoLS within the BSBMV p14 protein was revealed by the subcellular distribution pattern, identical to BNYVV p14 localization (Fig. 5D). Furthermore, we were able to identify the four essential cystein residues involved in the Znf formation that are conserved among benyvirus CRP (Fig. 1) and other known CRP (Koonin et al. 1991).

Except for the p14EGFP construct, histidine-tagged, EGFPp14 fusion protein and wt p14 expressed via the replicon vector were proven to be functional because they complemented efficiently an RNA2 $\Delta$ p14 mutant, leading to chlorotic local lesions and elevated virus multiplication levels similar to the wt. Therefore, because EG14 behaved like p14 and all the EGFPp14BA variants behaved similarly to p14BA mutants, we conclude that the $\mathrm{N}$-terminus-EGFP tag does not affect the intrinsic properties of p14 whereas the C-terminus fusion does.

Because all BNYVV p14 Znf and NoLS mutants replicated efficiently in protoplasts, the mutations introduced in the RNA2 p14 cistron did not interfere in cis with viral replication. Mutations affecting $\mathrm{Znf}$ folding decreased the stability of the corresponding EG14C ${ }^{68} \mathrm{~A}, \mathrm{EG} 14 \mathrm{C}^{71} \mathrm{~A}, \mathrm{EG} 14 \mathrm{C}^{105} \mathrm{~A}$, and EG14C ${ }^{108} \mathrm{~A}$ proteins. Similarly, we found a severe destabilization of the p14BA4 protein that was not detected even in the presence of wt p14, indicating the essential role of residues 94 to 97 and, particularly, $\mathrm{R}^{97}$ for its stability. BA1 to BA3 mutations resulted in only a partial destabilization of the proteins, which still possessed a residual silencing-suppression activity. This lower VSR activity was not due to the reduced amount of protein accumulation, as shown by the use of p14His, which conserved VSR activity despite its lower accumulation. This allows us to uncouple VSR activity and protein accumulation level. However, the comparison between patch test VSR assays with infection tests highlighted a possible stabilization of $\mathrm{p} 14$ protein in the viral context. The nature of such synergistic effect will require further investigation. Thus, the lower RNA accumulation of the NoLS-mutated p14BA1, p14BA2, and, to a lesser extent, p14BA3 (Fig. 4B) is linked to a decreased VSR activity. When wt EG14 or p14 protein were used in complementation tests, the necrotic centers disappeared from the lesions, indicating a link between necrosis and the absence (RNA1+2 $\Delta \mathrm{p} 14$ ) or disappearance of the VSR activity due to instability of the proteins at a later stage of infection (in the center of local lesions) and after 5 days post-agroinfiltration (data not shown).

Using biochemical and genetic tests, both benyvirus p14 proteins were shown to specifically form dimers (Fig. 5A and C). Only strongly self-interacting proteins were able to reach the nucleolus (p14 and p14-BA2), suggesting the requirement of a dimer formation for an efficient nucleolar targeting because nucleus- or nucleolus-distributing EG14-BA3 could interact with p14 and p14-BA2 but not with itself. EG14-BA1 and EG14-BA4 proteins merely diffused into the nucleus without reaching the nucleolus. The p14 nucleolus targeting also requires a functional $\mathrm{Znf}$ domain, suggesting the role of the $\mathrm{Znf}$ in both dimerization and protein stability. This highlights the outstanding importance of the ZnF-embedded NoLS stretch because some of the basic residues in NoLS are involved in the intrinsic properties of the $\mathrm{p} 14$ protein, as discussed above. Interestingly, the BdMoV p13 protein that efficiently complemented BNYVV- $\Delta$ p14 virus (Guilley et al. 2009) accumulated in the nucleus but never reached the nucleolus of the infected cells (this study; data not shown) and no NoLS was predicted with NoD algorithm. Taken together, these results allow us to conclude that p14 silencing-suppression activity requires a functional Znf domain and NoLS basic rich residues but not the nucleolar localization of the protein.

The nucleolus gathers various functions from ribosome biogenesis in response against cellular stresses that are tightly regulated (Emmott and Hiscox 2009) and, therefore, are the target of viral pathogenesis factors (Hiscox 2007; Hiscox et al. 2010). Cytoplasmic replicative Nidovirales members such as Arterivirus and Coronavirus spp. require nucleolar targeting of their nucleocapsid protein $(\mathrm{N})$ for efficient replication (Lee et al. 2006; Pei et al. 2008) that also involve interaction of the $\mathrm{N}$ proteins with fibrillarin (Yoo et al. 2003) or nucleolin (Chen et al. 2002), respectively. Some plant viruses are reported to produce proteins that similarly localize to the nucleolus and may influence viral outcome (e.g., Alfalfa mosaic virus $\mathrm{CP}$ whose NoLS motif appears important for both positive-strand accumulation and viral movement) (Herranz et al. 2012). In the case of Ourmiavirus spp., viral CP was also shown to localize in the nucleolus (Crivelli et al. 2011) but the incidence of such localization on the viral cycle has not been investigated. Another example is the Beet black scorch virus $\mathrm{P} 7 \mathrm{a}$ movement protein that possesses basic residues crucial for nuclear and nucleolar localizations and virus infection (Wang et al. 2012).

As stated before, our experiments and previous studies rule out the direct involvement of p14 in the replication and cell-tocell movement of BNYVV (Guilley et al. 2009). However, umbraviruses use fibrillarin and Cajal bodies for efficient longdistance spread within the plant host (Kim et al. 2007a and b). This leads to the important issue addressed in this report. We showed a relationship between VSR activity and BNYVV long-distance movement. By replacing p14 of RNA2 by the NoLS p14 mutants, we were able to show unambiguously that p14 protein is involved in long-distance movement. When inoculated to $N$. benthamiana plants, efficient viral systemic movement clearly occurred in the presence of RNA1 and RNA2-BA3. Although viral products were detected at a lower detection limit, BA1 was able to spread in the upper part of the plant at a decreased efficiency that could be linked to the weaker $\mathrm{CP}$ accumulation observed previously. When tested on B. macrocarpa, only p14-BA3 mutant was able to promote systemic movement of the virus, suggesting some cooperative effect of viral products on the p14 VSR that could not occur in agroinfiltration assays. In conclusion, p14 is essential for an efficient spread of BNYVV that appears unrelated to the nucleolar localization or to the dimer formation of p14. Thus, p14 CRP properties mark up a difference with the CMV 2b protein. It is not yet known which p14-nucleolar partners are recruited in the nucleolus during the viral cycle or for which purpose. Further proteomic studies, including pull-down analyses of the p14 protein partners obtained from nucleoli purified from BNYVV-infected cells, will provide some clues about the targets of the $\mathrm{p} 14$ protein.

\section{MATERIALS AND METHODS}

\section{Silencing suppression}

in GFP-silenced $N$. benthamiana $16 \mathrm{C}$ by virus infection.

GFP-silenced plants were prepared by infiltration of A. tumefaciens C58 carrying pBin-GFP to expanded leaves of $N$. benthamiana 16C, as previously described (Voinnet et al. 1998). BNYVV was inoculated to a noninfiltrated leaf after 20 days. 
Recovery of GFP expression was monitored by the observation of fluorescence under UV light and photographed 2 weeks after inoculation.

\section{Agroinfiltration of $N$. benthamiana.}

Agrobacteria were grown overnight at $28^{\circ} \mathrm{C}$ in Luria-Bertani medium supplemented with kanamycin $(100 \mu \mathrm{g} / \mathrm{ml})$ and rifampicin $(50 \mu \mathrm{g} / \mathrm{ml})$. Cells were centrifuged, washed, and resuspended to an optical density of 0.6 in $10 \mathrm{mM} \mathrm{MgCl}_{2}$ and 200 $\mu \mathrm{M}$ acetosyringone. Patch test and primary and secondary siRNA detection were performed as described (Bortolamiol et al. 2007; Kozlowska-Makulska et al. 2010). Briefly, leaves of $N$. benthamiana wt and $16 \mathrm{C}$ were agroinfiltrated with a mixture of A. tumefaciens cells (strain GV3101) containing pBin61 binary vectors carrying no VSR (-), TuYV P0 (Pfeffer et al. 2002), TCV p38 (Deleris et al. 2006), or BNYVV p14; or p14His, BSBMV p14, or HAp14 GFP and GF-FG hairpin sequences.

The binary vector $\mathrm{pBin}-\mathrm{GFP}$ and $\mathrm{pBin}-\mathrm{GF}-\mathrm{FG}$ constructs were described elsewhere (Himber et al. 2003). BNYVV p14 and p14His were polymerase chain reaction (PCR) amplified with specific primers and cloned into pBin61 using the SmaI site. BSBMV p14 and p14HA amplicons were obtained from reverse-transcribed cDNA of the BSBMV MRM infectious isolate (Ratti et al. 2009) using specific primer sets. Fragments were digested with $N c o$ I and BamHI, filled in using Klenow (Promega France SARL, Charbonniéres-les-Bains, France), and introduced into the pBin61 SmaI site to produce pBinp14BS and pBin-HA14BS. Restriction analyses and DNA sequencing validated all clones.

\section{BNYVV infectious clones expressing wt and modified benyvirus CRP.}

The full-length BNYVV clones for RNA1 and RNA2 (pB15 and pB2-14) were used as previously described (Hehn et al. 1995; Quillet et al. 1989). The p14 mutant RNA2 clones were constructed based on $\mathrm{pB} 2-14$ by the replacement of the region encompassing the p14 gene, between $\mathrm{XbaI}$ and StuI sites. A stop codon was introduced in frame to obtain RNA2 $\Delta \mathrm{p} 14$ (pB2-3722) (Hehn et al. 1995; Kozlowska-Makulska et al. 2010). All point mutations and some deletions were obtained by overlapping PCR-based mutagenesis. Sequence replacements for p14-BA mutants (pB2-BA1 to $\mathrm{pB} 2-4)$ were conducted similarly. The RNA-3-based replicon vector, pRep0, was used as an expression vector for desired proteins (Schmidlin et al. 2005; Vetter et al. 2004). The genes coding for BNYVV p14 and its variants were inserted into pRep0 within the BamHI site (pRep14, pRep14-BA1 to pRep14-4, and pRep14His). The pRepEGFP clone (Vetter et al. 2004) was used to produce BSBMV-p14-expressing replicons pRep14BS and pRepHA14BS by replacing the EGFP NcoI and BamHI fragment with p14BS- or HA-p14BS-digested amplicons. All pRepEGFPp14 fusions were generated by the introduction of the p14 sequences within $\mathrm{XmaI}$ and BamHI restriction sites (pRepEG14 and variants). The p14-EGFP construct was obtained by the replacement of the BNYVV p42 sequence within Rep42EGFP (Erhardt et al. 2000) by the p14 sequence using NcoI and XmaI restriction enzymes. All clones were validated by both restriction analyses and DNA sequencing.

\section{In vitro transcription and infection procedures.}

Full-length infectious clones of BNYVV and derivatives were transcribed in vitro as described previously (Hehn et al. 1995; Kozlowska-Makulska et al. 2010; Quillet et al. 1989; Schmidlin et al. 2005; Valentin et al. 2005) and served to infect $C$. quinoa, $N$. benthamiana, and B. macrocarpa leaves and BY-2 protoplasts using the usual procedures (Guilley et al.
2009; Klein et al. 2007; Rahim et al. 2007; Ratti et al. 2009; Valentin et al. 2005).

\section{RNA analyses.}

Agroinfiltrated patches or virus-infected tissues (pool of three local lesions or systemic leaf) were subjected to RNA extraction using TRIzol reagent following the manufacturer's recommendations. Protoplast RNA contents were purified using Polysomes buffer and phenol extraction followed by ethanol precipitation (Gilmer et al. 1992; Hehn et al. 1995). NB experiments were conducted as described previously using $12 \mu \mathrm{g}$ of total RNA for siRNA analyses, $5 \mu \mathrm{g}$ of total RNA for GFP mRNA detection, and the equivalent of one C. quinoa local lesion content (Bortolamiol et al. 2007; Guilley et al. 2009; Klein et al. 2007; Kozlowska-Makulska et al. 2010). When possible, RNA samples were adjusted at the same concentration and visualized on ethidium bromide-stained agarose gels. Specific ${ }^{32}$ P-radiolabeled GFP or "GF" and "P" cDNA probes were used for hybridization of high and low molecular weight RNAs, respectively, as described (Himber et al. 2003). Detection of viral RNAs was performed as already described (Klein et al. 2007).

\section{Protein analyses.}

Agroinfiltrated leaves, systemic leaves, and pools of three local lesions were subjected to protein extraction using Laemmli buffer (Laemmli 1970), as described previously (Klein et al. 2007; Kozlowska-Makulska et al. 2010). Total protein extracts were heat denaturated and subjected to SDSPAGE separation followed by the transfer onto Immobilon membranes. Immunodetections were performed as already described (Klein et al. 2007).

\section{Yeast two-hybrid.}

Experiments were performed as described previously (Klein et al. 2007) following the Clontech manufacturer's recommendations. Benyvirus CRP bait and prey sequences were cloned in frame with GAL4 BD (pGBKT7) and AD (pGADT7) using EcoRI or XmaI and SalI or XhoI restriction sites, respectively.

\section{BY-2 transient expression, CLSM, and FRET-FLIM analyses.}

BSBMV p14 sequence was amplified with a specific set of primers. The amplicon was digested with $X m a \mathrm{I} / X b a \mathrm{I}$ and inserted in the pCK-EGFP and pCK-mRFP vectors using the same restriction sites. EGFP and mRFP fusion proteins (GFPp14BS and RFPp14BS) were transiently expressed and visualized in BY-2 tobacco cells as described (Vetter et al. 2004). Lifetimes of EGFP-p14BS fluorescence were measured in the presence or absence of the mRFP-p14BS construct after $24 \mathrm{~h}$ by using the LIFA frequency domain fluorescence lifetime imaging system (Lambert Instruments, Roden, The Netherlands).

\section{ACKNOWLEDGMENTS}

We thank H. Kondo for sharing the BdMoV p13 clone, S. Pfeffer for the BNYVV silencing-suppression unpublished results, A. Hehn for some p14 mutants used in this study, M. Erhardt for the electron microscopy imaging, J. Mutterer for the FRET-FLIM analyses, M. Alioua for the DNA sequencing, C. Mounier for her technical assistance, and D. Scheidecker for the protoplasts isolation.

\section{LITERATURE CITED}

Andika, I. B., Kondo, H., and Tamada, T. 2005. Evidence that RNA silencing-mediated resistance to beet necrotic yellow vein virus is less effective in roots than in leaves. Mol. Plant-Microbe Interact. 18:194-204. 
Andika, I. B., Kondo, H., Nishiguchi, M., and Tamada, T. 2012. The cysteine-rich proteins of Beet necrotic yellow vein virus and Tobacco rattle virus contribute to efficient suppression of silencing in roots. J. Gen. Virol. 93:1841-1850.

Angell, S. M., and Baulcombe, D. C. 1997. Consistent gene silencing in transgenic plants expressing a replicating potato virus X RNA. EMBO (Eur. Mol. Biol. Organ.) J. 16:3675-3684

Azevedo, J., Garcia, D., Pontier, D., Ohnesorge, S., Yu, A., Garcia, S., Braun, L., Bergdoll, M., Hakimi, M. A., Lagrange, T., and Voinnet, O. 2010. Argonaute quenching and global changes in dicer homeostasis caused by a pathogen-encoded GW repeat protein. Genes Dev. 24:904915

Baltimore, D. 1971. Expression of animal virus genomes. Bacteriol. Rev. 35:235-241.

Bortolamiol, D., Pazhouhandeh, M., Marrocco, K., Genschik, P., and Ziegler-Graff, V. 2007. The Polerovirus F box protein P0 targets ARGONAUTE1 to suppress RNA silencing. Curr. Biol. 17:1615-1621.

Brigneti, G., Voinnet, O., Li, W.X., Ji, L. H., Ding, S. W., and Baulcombe, D. C. 1998. Viral pathogenicity determinants are suppressors of transgene silencing in Nicotiana benthamiana. EMBO (Eur. Mol. Biol. Organ.) J. 17:6739-6746.

Brigneti, G., Martin-Hernandez, A. M., Jin, H., Chen, J., Baulcombe, D. C., Baker, B., and Jones, J. D. 2004. Virus-induced gene silencing in Solanum species. Plant J. 39:264-272.

Burgyan, J., and Havelda, Z. 2011. Viral suppressors of RNA silencing. Trends Plant Sci. 16:265-272.

Chen, H., Wurm, T., Britton, P., Brooks, G., and Hiscox, J.A. 2002. Interaction of the coronavirus nucleoprotein with nucleolar antigens and the host cell. J. Virol. 76:5233-5250.

Chiba, S., Kondo, H., Miyanishi, M., Andika, I. B., Han, C., and Tamada, T. 2011. The evolutionary history of Beet necrotic yellow vein virus deduced from genetic variation, geographical origin and spread, and the breaking of host resistance. Mol. Plant-Microbe Interact. 24:207-218.

Crivelli, G., Ciuffo, M., Genre, A., Masenga, V., and Turina, M. 2011. Reverse genetic analysis of Ourmiaviruses reveals the nucleolar localization of the coat protein in Nicotiana benthamiana and unusual requirements for virion formation. J. Virol. 85:5091-5104.

Deleris, A., Gallego-Bartolome, J., Bao, J., Kasschau, K. D., Carrington, J. C., and Voinnet, O. 2006. Hierarchical action and inhibition of plant dicer-like proteins in antiviral defense. Science 313:68-71.

Diaz-Pendon, J. A., and Ding, S. W. 2008. Direct and indirect roles of viral suppressors of RNA silencing in pathogenesis. Annu. Rev. Phytopathol. 46:303-326

Ding, S. W. 2010. RNA-based antiviral immunity. Nat. Rev. Immunol. 10:632-644

Ding, S. W., and Voinnet, O. 2007. Antiviral immunity directed by small RNAs. Cell 130:413-426.

Duan, C. G., Fang, Y. Y., Zhou, B. J., Zhao, J. H., Hou, W. N., Zhu, H., Ding, S. W., and Guo, H. S. 2012. Suppression of Arabidopsis ARGONAUTE1-mediated slicing, transgene-induced RNA silencing, and DNA methylation by distinct domains of the Cucumber mosaic virus $2 \mathrm{~b}$ protein. Plant Cell 24:259-274.

Dunoyer, P., Pfeffer, S., Fritsch, C., Hemmer, O., Voinnet, O., and Richards, K. E. 2002. Identification, subcellular localization and some properties of a cysteine-rich suppressor of gene silencing encoded by peanut clump virus. Plant J. 29:555-567.

Dunoyer, P., Lecellier, C. H., Parizotto, E. A., Himber, C., and Voinnet, O. 2004. Probing the microRNA and small interfering RNA pathways with virus-encoded suppressors of RNA silencing. Plant Cell 16:1235-1250.

Emmott, E., and Hiscox, J. A. 2009. Nucleolar targeting: The hub of the matter. EMBO (EUR. MOL. BIOL. ORGAN.) Rep. 10:231-238.

Erhardt, M., Morant, M., Ritzenthaler, C., Stussi-Garaud, C., Guilley, H., Richards, K., Jonard, G., Bouzoubaa, S., and Gilmer, D. 2000. P42 movement protein of Beet necrotic yellow vein virus is targeted by the movement proteins P13 and P15 to punctate bodies associated with plasmodesmata. Mol. Plant-Microbe Interact. 13:520-528.

Gilmer, D., and Ratti, C. 2012. Benyvirus. Pages 1133-1138 in: Virus Taxonomy: Classification and Nomenclature of Viruses: Ninth Report of the International Committee on Taxonomy of Viruses. A. M. Q. King, M. J. Adams, E. B. Carstens, and E. J. Lefkowitz, eds. Elsevier, San Diego, CA, U.S.A.

Gilmer, D., Bouzoubaa, S., Hehn, A., Guilley, H., Richards, K., and Jonard, G. 1992. Efficient cell-to-cell movement of beet necrotic yellow vein virus requires $3^{\prime}$ proximal genes located on RNA 2. Virology 189:40-47.

Gonzalez, I., Martinez, L., Rakitina, D. V., Lewsey, M. G., Atencio, F.A., Llave, C., Kalinina, N. O., Carr, J. P., Palukaitis, P., and Canto, T. 2010. Cucumber mosaic virus $2 \mathrm{~b}$ protein subcellular targets and interactions: Their significance to RNA silencing suppressor activity. Mol. PlantMicrobe Interact. 23:294-303.
Gonzalez, I., Rakitina, D., Semashko, M., Taliansky, M., Praveen, S., Palukaitis, P., Carr, J. P., Kalinina, N., and Canto, T. 2012. RNA binding is more critical to the suppression of silencing function of Cucumber mosaic virus $2 \mathrm{~b}$ protein than nuclear localization. RNA 18:771-782.

Guilley, H., Bortolamiol, D., Jonard, G., Bouzoubaa, S., and Ziegler-Graff, V. 2009. Rapid screening of RNA silencing suppressors by using a recombinant virus derived from beet necrotic yellow vein virus. J. Gen. Virol. 90:2536-2541.

Hehn, A., Bouzoubaa, S., Bate, N., Twell, D., Marbach, J., Richards, K. Guilley, H., and Jonard, G. 1995. The small cysteine-rich protein P14 of beet necrotic yellow vein virus regulates accumulation of RNA 2 in cis and coat protein in trans. Virology 210:73-81.

Herranz, M. C., Pallas, V., and Aparicio, F. 2012. Multifunctional roles for the N-terminal basic motif of Alfalfa mosaic virus coat protein: Nucleolar/cytoplasmic shuttling, modulation of RNA-binding activity, and virion formation. Mol. Plant-Microbe Interact. 25:1093-1103.

Himber, C., Dunoyer, P., Moissiard, G., Ritzenthaler, C., and Voinnet, O. 2003. Transitivity-dependent and -independent cell-to-cell movement of RNA silencing. EMBO (Eur. Mol. Biol. Organ.) J. 22:4523-4533.

Hiscox, J. A. 2007. RNA viruses: Hijacking the dynamic nucleolus. Nat. Rev. Microbiol. 5:119-127.

Hiscox, J. A., Whitehouse, A., and Matthews, D. A. 2010. Nucleolar proteomics and viral infection. Proteomics 10:4077-4086.

Jupin, I., Richards, K., Jonard, G., Guilley, H., and Pleij, C. W. 1990. Mapping sequences required for productive replication of beet necrotic yellow vein virus RNA 3. Virology 178:273-280.

Katoh, K., and Toh, H. 2008. Recent developments in the MAFFT multiple sequence alignment program. Brief. Bioinf. 9:286-298.

Kim, S. H., Macfarlane, S., Kalinina, N. O., Rakitina, D. V., Ryabov, E. V., Gillespie, T., Haupt, S., Brown, J. W., and Taliansky, M. 2007a. Interaction of a plant virus-encoded protein with the major nucleolar protein fibrillarin is required for systemic virus infection. Proc. Natl. Acad. Sci. U.S.A. 104:11115-11120.

Kim, S. H., Ryabov, E. V., Kalinina, N. O., Rakitina, D. V., Gillespie, T., MacFarlane, S., Haupt, S., Brown, J. W., and Taliansky, M. 2007b. Cajal bodies and the nucleolus are required for a plant virus systemic infection. EMBO (Eur. Mol. Biol. Organ.) J. 26:2169-2179.

Klein, E., Link, D., Schirmer, A., Erhardt, M., and Gilmer, D. 2007. Sequence variation within Beet necrotic yellow vein virus p25 protein influences its oligomerization and isolate pathogenicity on Tetragonia expansa. Virus Res. 126:53-61.

Koonin, E. V., Boyko, V. P., and Dolja, V. V. 1991. Small cysteine-rich proteins of different groups of plant RNA viruses are related to different families of nucleic acid-binding proteins. Virology 181:395-398.

Kozlowska-Makulska, A., Guilley, H., Szyndel, M. S., Beuve, M. Lemaire, O., Herrbach, E., and Bouzoubaa, S. 2010. P0 proteins of European beet-infecting poleroviruses display variable RNA silencing suppression activity. J. Gen. Virol. 91:1082-1091.

Laemmli, U. K. 1970. Cleavage of structural proteins during the assembly of the head of bacteriophage T4. Nature 227:680-685.

Lauber, E., Bleykasten-Grosshans, C., Erhardt, M., Bouzoubaa, S., Jonard, G., Richards, K.E., and Guilley, H. 1998. Cell-to-cell movement of beet necrotic yellow vein virus: I. Heterologous complementation experiments provide evidence for specific interactions among the triple gene block proteins. Mol. Plant-Microbe Interact. 11:618-625.

Lee, C., Hodgins, D., Calvert, J. G., Welch, S. K., Jolie, R., and Yoo, D. 2006. Mutations within the nuclear localization signal of the porcine reproductive and respiratory syndrome virus nucleocapsid protein attenuate virus replication. Virology 346:238-250.

Li, F., and Ding, S. W. 2006. Virus counterdefense: Diverse strategies for evading the RNA-silencing immunity. Annu. Rev. Microbiol. 60:503531.

Lozano, I., and Morales, F. 2009. Molecular characterisation of Rice stripe necrosis virus as a new species of the genus Benyvirus. Eur. J. Plant Pathol. 124:673-680.

Moissiard, G., and Voinnet, O. 2006. RNA silencing of host transcripts by Cauliflower mosaic virus requires coordinated action of the four Arabidopsis dicer-like proteins. Proc. Natl. Acad. Sci. U.S.A. 103:1959319598.

Moissiard, G., Parizotto, E. A., Himber, C., and Voinnet, O. 2007. Transitivity in Arabidopsis can be primed, requires the redundant action of the antiviral dicer-like 4 and dicer-like 2, and is compromised by viralencoded suppressor proteins. RNA 13:1268-1278.

Niesbach-Klosgen, U., Guilley, H., Jonard, G., and Richards, K. 1990. Immunodetection in vivo of beet necrotic yellow vein virus-encoded proteins. Virology 178:52-61.

Pei, Y., Hodgins, D. C., Lee, C., Calvert, J. G., Welch, S. K., Jolie, R., Keith, M., and Yoo, D. 2008. Functional mapping of the porcine reproductive and respiratory syndrome virus capsid protein nuclear localization signal and its pathogenic association. Virus Res. 135:107-114. 
Peltier, C., Hleibieh, K., Thiel, H., Klein, E., Bragard, C., and Gilmer, D. 2008. Molecular biology of the Beet necrotic yellow vein virus. Plant Viruses 2:14-24.

Peltier, C., Klein, E., Hleibieh, K., D’Alonzo, M., Hammann, P., Bouzoubaa, S., Ratti, C., and Gilmer, D. 2012. Beet necrotic yellow vein virus subgenomic RNA3 is a cleavage product leading to stable non-coding RNA required for long-distance movement. J. Gen. Virol. 93:1093-1102.

Pfeffer, S., Dunoyer, P., Heim, F., Richards, K. E., Jonard, G., and ZieglerGraff, V. 2002. P0 of Beet western yellows virus is a suppressor of posttranscriptional gene silencing. J. Virol. 76:6815-6824.

Quillet, L., Guilley, H., Jonard, G., and Richards, K. 1989. In vitro synthesis of biologically active beet necrotic yellow vein virus RNA. Virology 172:293-301.

Rahim, M. D., Andika, I. B., Han, C., Kondo, H., and Tamada, T. 2007. RNA4-encoded p31 of Beet necrotic yellow vein virus is involved in efficient vector transmission, symptom severity and silencing suppression in roots. J. Gen. Virol. 88:1611-1619.

Ratcliff, F., Martin-Hernandez, A. M., and Baulcombe, D. C. 2001. Technical advance. Tobacco rattle virus as a vector for analysis of gene function by silencing. Plant J. 25:237-245.

Ratti, C., Hleibieh, K., Bianchi, L., Schirmer, A., Autonell, C. R., and Gilmer, D. 2009. Beet soil-borne mosaic virus RNA-3 is replicated and encapsidated in the presence of BNYVV RNA-1 and -2 and allows long distance movement in Beta macrocarpa. Virology 385:392-399.

Ruiz-Ferrer, V., and Voinnet, O. 2007. Viral suppression of RNA silencing: 2b wins the Golden Fleece by defeating Argonaute. Bioessays 29:319323

Schirmer, A., Link, D., Cognat, V., Moury, B., Beuve, M., Meunier, A., Bragard, C., Gilmer, D., and Lemaire, O. 2005. Phylogenetic analysis of isolates of Beet necrotic yellow vein virus collected worldwide. J. Gen. Virol. 86:2897-2911.

Schmidlin, L., Link, D., Mutterer, J., Guilley, H., and Gilmer, D. 2005. Use of a Beet necrotic yellow vein virus RNA-5-derived replicon as a new tool for gene expression. J. Gen. Virol. 86:463-467.

Scott, M. S., Troshin, P.V., and Barton, G. J. 2011. NoD: A nucleolar lo- calization sequence detector for eukaryotic and viral proteins. BMC Bioinformatics 12:317.

Valentin, C., Dunoyer, P., Vetter, G., Schalk, C., Dietrich, A., and Bouzoubaa, S. 2005. Molecular basis for mitochondrial localization of viral particles during beet necrotic yellow vein virus infection. J. Virol. 79:9991 10002 .

Vetter, G., Hily, J. M., Klein, E., Schmidlin, L., Haas, M., Merkle, T., and Gilmer, D. 2004. Nucleo-cytoplasmic shuttling of the Beet necrotic yellow vein virus RNA-3-encoded p25 protein. J. Gen. Virol. 85:2459-2469.

Voinnet, O. 2001. RNA silencing as a plant immune system against viruses. Trends Genet. 17:449-459.

Voinnet, O. 2005. Induction and suppression of RNA silencing: Insights from viral infections. Nat Rev Genet 6:206-220.

Voinnet, O. 2008. Post-transcriptional RNA silencing in plant-microbe interactions: A touch of robustness and versatility. Curr. Opin. Plant Biol. 11:464-470.

Voinnet, O., Vain, P., Angell, S., and Baulcombe, D. C. 1998. Systemic spread of sequence-specific transgene RNA degradation in plants is initiated by localized introduction of ectopic promoterless DNA. Cell 95:177-187.

Voinnet, O., Rivas, S., Mestre, P., and Baulcombe, D. 2003. An enhanced transient expression system in plants based on suppression of gene silencing by the p19 protein of Tomato bushy stunt virus. Plant J. 33:949-956.

Wang, X., Zhang, Y., Xu, J., Shi, L., Fan, H., Han, C., Li, D., and Yu, J. 2012. The R-rich motif of Beet black scorch virus P7a movement protein is important for the nuclear localization, nucleolar targeting and viral infectivity. Virus Res. 167:207-218

Yoo, D., Wootton, S. K., Li, G., Song, C., and Rowland, R. R. 2003. Colocalization and interaction of the porcine arterivirus nucleocapsid protein with the small nucleolar RNA-associated protein fibrillarin. J. Virol. 77:12173-12183.

Zhang, L., Wang, X., Li, D., Han, C., Zhai, Y., and Yu, J. 2005. Two virusencoded RNA silencing suppressors, P14 of Beet necrotic yellow vein virus and S6 of Rice black streak dwarf virus. Chin. Sci. Bull. 50:305-310. 